\title{
Experimental Study of Incipient Motion in Mixed-Size Sediment
}

\author{
Peter R. Wilcock ${ }^{1}$ AND John B. SOUTHARD
}

Department of Earth, Atmospheric, and Planetary Sciences, Massachusetts Institute of Technology, Cambridge

\begin{abstract}
Transport rates of five sediments were measured in a laboratory flume. Three of these sediments had the same mean size, the same size distribution shape, and different values of grain size distribution standard deviation. The critical shear stress for incipient motion of the individual size fractions within these sediments was estimated as that shear stress that produced a small dimensionless transport rate. The sorting of the sediment mixture had little effect on the critical shear stress of individual fractions, once the median size $\left(D_{50}\right)$ of the mixture and a fraction's relative size $\left(D_{0} / D_{s 0}\right)$ are accounted for. Our data, combined with previously published data, show a remarkably consistent relation between the critical shear stress of individual fractions and the fraction's relative grain size, despite a broad variation in the available data of mixture sorting, grain size distribution shape, mean grain size, and grain shape. All fractions in a size mixture begin moving at close to the same value of bed shear stress during steady state transport conditions. This result is apparently true for transport systems where the transport rates of individual fractions are determined solely by the flow and bed sediment (recirculating systems), as well as for systems where the fractional transport rates are imposed on the system (feed systems). This equivalence in initial-motion results is important because natural transporting systems often show attributes of both types of behavior in an unknown combination.
\end{abstract}

\section{INTRODUCTION}

In recent years much effort has been devoted to the critical shear stress at which individual size fractions in mixed-size sediments begin to move. In field studies the critical shear stress has been estimated from the largest grain observed in motion [Andrews, 1983; Carling, 1983; Hammond et al.., 1984]. Mixed-size sediment transport rates, from which incipient motion may be estimated, have been measured in several laboratory studies [Day, 1980a, b; Dhamotharan et al., 1980; Misri et al., 1984] and in the field [Milhous, 1973; Parker et al., 1982]. Experiments on part of the problem, the pivoting angle of individual size fractions, have been made by $L i$ and Komar [1986]. Wiberg and Smith [1987] have used the earlier pivoting angle results of Miller and Byrne [1966] in developing a semianalytical model of critical shear stress. All this work is motivated in part by the importance of the problem: the critical shear stress for individual size fractions is an integral component of mixed-size sediment transport models. It is almost important in problems like static armoring and channel stability. The recent work has also been motivated by the realization, supported by a growing body of data, that the critical shear stress of individal fractions in mixed-size sediment is considerably different from that of unisize sediments and from many earlier attempts to model it.

In all of the recent work, the initial-motion results for size mixtures are compared to the better understood case of unisize sediment. Although it is natural to compare a new relation to a better known existing one, this is also a necessary first step in defining general relations for initial motion which must hold for all mixtures, including the limiting case of unisize sediment. Attempts to define general initial-motion relations lor all mixtures have not been particularly successful [e.g. White and Day, 1982] and suffer in large part from the absence of data that fall between well sorted and poorly sorted sediments. This paper describes initial-motion results from

\footnotetext{
${ }^{1}$ Now at Department of Geography and Environmental Engineerung, The Johns Hopkins University, Baltimore, Maryland.

Copyright 1988 by the American Geophysical Union.

Paper Number 7W5074.

$0043-1397 / 88 / 007 \mathrm{~W}-5074 \$ 05.00$
}

flume transport experiments that were designed to bridge this gap by using sediments whose sorting varied from well sorted to poorly sorted $(0.18 \phi$ to $0.99 \phi)$. When combined with the existing transport data for mixed-size sediments, the data now available provide a fairly even coverage of sorting values from $0.18 \phi$ to $2.1 \phi$ (Table 1 ), which includes those typical of most natural sediments.

In addition to comparing initial-motion relations for unisize and poorly sorted sediments, it is of interest to test whether the mixture sorting itself has a direct and consistent influence on initial-motion values for individual size fractions. The motivation for such a test is the fact that the relative size of a fraction, which along with its absolute size largely controls its initial motion, is completely described for a given reasonably smooth distribution by three variables: the size ratio of the fraction (e.g., $D_{i} / D_{m}$, the ratio of the ith fraction to the mean grain size of the mixture), the percentile position of the fraction (e.g., percent finer than), and the mixture standard deviation $\sigma$. To date, only one of the relative-size parameters $\left(D_{l} / D_{m}\right.$ or percent finer than) has been used to model the initial motion of a size fraction. To test whether more than one of these parameters is needed to explain the variation in initial motion, three of the sediment mixtures in our experiments were made with the same mean size $(1.85 \mathrm{~mm})$ and grain size distribution shape (lognormal) but with sorting equal to 0.20 , 0.50 , and $0.99 \phi$. By also holding the flow depth and water temperature within a narrow range, we can isolate the effect of one size distribution variable (e.g., mixture sorting or the percentile position of a fraction in the mixture) on the initial motion of an individual fraction (specified by a particular value of $D_{i} / D_{m}$ ).

\section{Relative Size of Individual Fractions}

The grain size of an individual size fraction in a mixture has two effects, one absolute and the other relative, on the transport rate of that fraction. First, for a given grain density and shape, the absolute size of the fraction determines the mass of the grain and the area of grain surface exposed to the flow. Grain area is proportional to $D^{2}$ and grain mass is proportional to $D^{3}$, so the ratio of driving forces to resisting forces for each fraction is represented by the classic Shields parameter. 
TABLE 1. Size Distribution Parameters for Bed Sediments

\begin{tabular}{llllllll}
\hline Sediment & \multicolumn{1}{c}{ Reference } & $\begin{array}{l}D_{m}, \\
\mathrm{~mm}\end{array}$ & $\begin{array}{l}D_{15}, \\
\mathrm{~mm}\end{array}$ & $\begin{array}{l}D_{\text {so, }} \\
\mathrm{mm}\end{array}$ & $\begin{array}{l}D_{\mathbf{8} 5}, \\
\mathrm{~mm}\end{array}$ & $\sigma_{\phi}{ }^{*}$ & $\sigma_{\mathbf{g}}^{\dagger}$ \\
\hline MIT MUNI & Wilcock [1987] & 1.87 & 1.63 & 1.86 & 2.20 & 0.20 & 1.15 \\
MIT 1/2 $\phi$ & Wilcock [1987] & 1.82 & 1.25 & 1.83 & 2.59 & 0.50 & 1.41 \\
MIT 1/ $\phi$ & Wilcock [1987] & 1.85 & 0.893 & 1.83 & 3.88 & 0.99 & 1.99 \\
MIT FUNI & Wilcock [1987] & 0.662 & 0.538 & 0.670 & 0.807 & 0.26 & 1.20 \\
MIT CUNI & Wilcock [1987] & 5.31 & 4.68 & 5.28 & 6.17 & 0.18 & 1.13 \\
DAY A & Day [1980a] & 1.50 & 0.336 & 1.82 & 6.05 & 1.77 & 3.41 \\
DAY B & Day [1980a] & 1.17 & 0.318 & 1.57 & 3.49 & 1.45 & 2.73 \\
MISRI N1 & Misri et al. [1984] & 2.37 & 1.15 & 2.36 & 4.91 & 1.00 & 2.00 \\
MISRI N2 & Misri et al. [1984] & 3.78 & 1.21 & 3.81 & 11.9 & 1.44 & 2.71 \\
MISRI N3 & Misri et al. [1984] & 4.09 & 1.70 & 4.00 & 10.1 & 1.18 & 2.27 \\
SAF & Dhamotharan & 2.10 & 0.828 & 2.16 & 6.04 & 1.29 & 2.45 \\
& $\quad$ et al. [1980] & & & & & & \\
Oak Creek & Milhous [1973] & 13.1 & 2.37 & 19.5 & 56.6 & 2.10 & 4.29 \\
\hline
\end{tabular}

*Here $\sigma_{\phi}$ is the standard deviation of the size distribution when expressed in $\phi$ units.

†Here $\sigma_{g}=2^{\left(\omega_{\phi}\right)} \sigma g$ is the geometric standard deviation of the size distribution in millimeters.

$$
\tau_{i}^{*}=\frac{\tau_{0}}{(s-1) \rho g D_{i}}
$$

where $\tau_{0}$ is bed shear stress, $\rho$ is fluid density, $s$ is the ratio of grain density to fluid density, $g$ is acceleration due to gravity, and $D_{l}$ is size of the $i$ th fraction. For grains in a unisize bed and a given $\tau_{0}$, the ratio of driving to resisting forces, and hence the transport rate, increases with decreasing grain size. The size of each grain relative to others in the mixture controls the variation from fraction to fraction of both the value of bed shear stress acting on individual grains and the resistence of those grains to movement. Because smaller grains in a mixture are more hidden from the flow and also more impeded in their motion than coarser grains, the relative-size effect counteracts the absolute-size effect by decreasing the mobility of the finer fractions and increasing the mobility of the coarser fractions. The essence of the mixed-size sediment transport problem lies in the balance between these two grainsize effects.

Because of its central role in mixed-size sediment transport, the relative size of each fraction must be described accurately. For the general case of a reasonably smooth grain size distribution, relative grain size is completely described by three variables: the size ratio of the fraction (e.g., $D_{V} / D_{m}$ ), the percentile position of the fraction (e.g., percent finer than, $P$ ) and the mixture standard deviation $\sigma$. For a smooth size distribution reasonably symmetrical about its mean, two of these three variables are sufficient to describe the relative size of a fraction. For example, for a lognormal distribution (which we used in our experiments), the three are exactly related as

$$
P=\frac{100}{(2 \pi)^{1 / 2}} \int_{-\infty}^{z} e^{-t^{2} / 2} d t
$$

where

$$
z=\frac{\log _{2}\left(D_{i} / D_{m}\right)}{\sigma_{\phi}}
$$

and $\sigma_{\phi}$ is the mixture standard deviation in $\phi$ units $(\phi=$ $-\log _{2} D$, where $D$ is grain size in $\mathrm{mm}$ ). The variation of $P$ with $\sigma_{\phi}$ for a range of $D_{i} / D_{m}$, shown for lognormal size distributions in Figure 1, illustrates the potential need for considering more than one relative-size parameter. Following the curve for $D_{i} / D_{m}=2$ in Figure $1, \sigma_{\phi}=0.5$ corresponds to $P=98 \%$ finer than; at $\sigma_{\phi}=2.0$, a value common for gravel bed streams, $P=68 \%$ finer than, representing a substantial change in the relative position of the same fraction. It is not clear that the transport rates for the fraction $D_{i} / D_{m}=2$ (including a low reference transport rate used to estimate $\tau_{e i}$ of the fraction would be the same for both mixtures. Because most studies on initial motion have represented relative grain size by one or the other of $D_{i} / D_{50}$ or $P$, a direct test of this approximation was a goal of this work.

\section{EXPERIMENTAL METHODS}

We made 29 experimental runs with five different sediments. The mean hydraulic and transport parameters are given in Tables 2 and 3. Where appropriate, estimates (based on variability in the experimental data) are given of the error in these measurements. Detail on the experimental method is provided in the work by Wilcock [1987].

\section{Apparatus}

The experiments were made in a flume with a channel $23 \mathrm{~m}$ long, $0.6 \mathrm{~m}$ wide, and $0.3 \mathrm{~m}$ deep. Water and sediment were recirculated separately. The upstream $6 \mathrm{~m}$ of the channel contained a false bottom at the same elevation as the sediment bed. Sand $1.83-2.00 \mathrm{~mm}$ in diameter (the mean size of the principal sediment mixtures used in the study) was glued to the downstream $4.9 \mathrm{~m}$ of the false bottom to allow the boundary layer to develop before it reached the movable bed. The $16.2-\mathrm{m}$ working section of the bed ended in a sediment trap

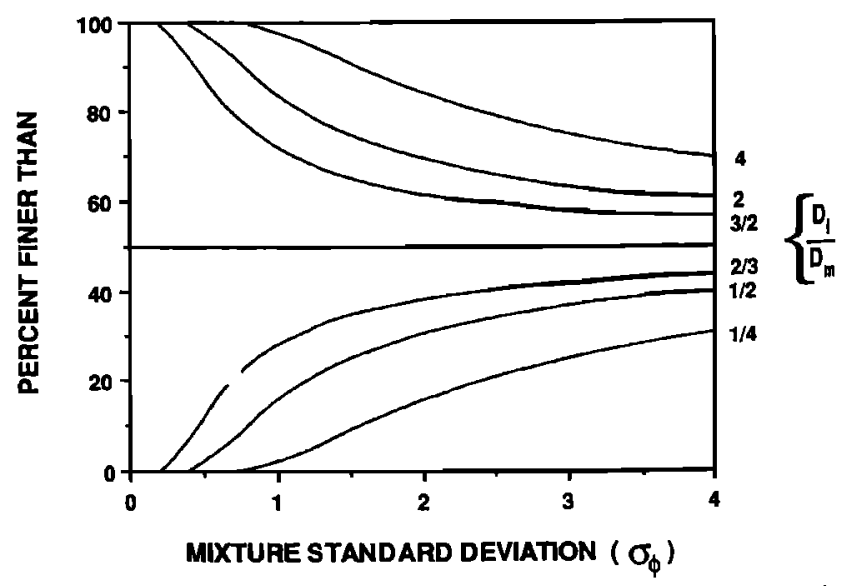

Fig. 1. General relation between $D_{i} / D_{m}$, percent finer than, and mixture sorting. 
TABLE 2. Measured Hydraulic Parameters for MIT Experiments

\begin{tabular}{|c|c|c|c|c|c|c|c|c|c|c|}
\hline Mixture & Run & $\begin{array}{c}\text { Mean } \\
\text { Depth, } \\
\text { cm }\end{array}$ & $\begin{array}{c}\text { Depth } \\
\text { Error } \\
\text { at } \\
90 \% \text {, } \\
\pm \%\end{array}$ & $\begin{array}{c}\text { Water } \\
\text { Surface } \\
\text { Slope, } \\
\times 10^{4}\end{array}$ & $\begin{array}{c}\text { Slope } \\
\text { Error } \\
\text { at } \\
90 \% \\
\pm \%\end{array}$ & $\begin{array}{c}\text { Water } \\
\text { Discharge } \\
\times 10^{3} \\
\mathrm{~m}^{3} / \mathrm{s}\end{array}$ & $\begin{array}{c}\text { Discharge } \\
\text { Error } \\
\text { at } 90 \% \\
\pm \%\end{array}$ & $\begin{array}{c}\text { Mean } \\
\text { Velocity } \\
\mathrm{cm} / \mathrm{s}\end{array}$ & $\begin{array}{c}\text { Water } \\
\text { Temperature } \\
{ }^{\circ} \mathrm{C}\end{array}$ & $\begin{array}{c}\text { Run } \\
\text { Duration, } \\
\text { hours }\end{array}$ \\
\hline \multirow[t]{6}{*}{ MUNI } & $\mathrm{A} 2$ & 11.4 & 0.3 & 9.6 & - & 30.6 & 1.5 & 44.8 & 25.1 & 7.2 \\
\hline & $\mathrm{A} 3$ & 11.4 & 0.4 & 12.4 & 2.6 & 35.3 & 1.5 & 51.8 & 25.5 & 5.5 \\
\hline & A4 & 11.5 & 0.6 & 14.2 & 13.1 & 39.7 & 1.4 & 57.6 & 24.5 & 16.5 \\
\hline & A5 & 11.8 & 1.0 & 21.5 & 6.5 & 43.6 & 1.4 & 61.8 & 25.9 & 13.2 \\
\hline & A6 & 12.0 & 1.1 & 24.2 & 12.5 & 48.8 & 1.3 & 67.5 & 24.1 & 5.9 \\
\hline & A7 & 12.8 & 1.4 & 29.3 & 14.9 & 55.7 & 1.3 & 72.4 & 25.0 & 7.1 \\
\hline \multirow{7}{*}{$1 / 2 \phi$} & B1 & 11.0 & 0.6 & 10.0 & 2.9 & 28.7 & 1.5 & 43.6 & 25.5 & 29.8 \\
\hline & B2 & 11.2 & 1.6 & 10.3 & 3.0 & 30.4 & 1.5 & 45.3 & 24.5 & 30.9 \\
\hline & B3 & 11.2 & 1.0 & 12.6 & 5.3 & 35.6 & 1.5 & 52.8 & 24.8 & 28.2 \\
\hline & B4 & 11.3 & 1.4 & 16.8 & 4.9 & 39.3 & 1.4 & 58.0 & 26.4 & 27.5 \\
\hline & B5 & 11.6 & 1.5 & 21.4 & 8.4 & 43.4 & 1.4 & 62.2 & 25.9 & 23.5 \\
\hline & B6 & 11.7 & 1.4 & 33.4 & 10.1 & 47.7 & 1.3 & 67.9 & 24.4 & 19.5 \\
\hline & B7 & 11.5 & 2.6 & 49.2 & 9.7 & 54.9 & 1.3 & 79.4 & 25.0 & 6.1 \\
\hline \multirow{6}{*}{$1 \phi$} & $\mathrm{Cl}$ & 11.1 & 0.8 & 10.4 & 4.0 & 28.6 & 1.5 & 43.1 & 25.4 & 39.2 \\
\hline & C2 & 10.9 & 0.4 & 11.1 & 1.8 & 30.3 & 1.5 & 46.5 & 24.7 & 38.5 \\
\hline & C3 & 11.2 & 2.1 & 18.2 & 3.2 & 35.0 & 1.5 & 52.4 & 24.7 & 34.4 \\
\hline & $\mathrm{C} 4$ & 11.2 & 1.7 & 21.4 & 5.9 & 39.1 & 1.4 & 58.0 & 24.9 & 31.3 \\
\hline & C5 & 11.0 & 2.0 & 28.0 & 9.9 & 43.4 & 1.4 & 65.5 & 23.6 & 27.3 \\
\hline & C6 & 10.9 & 2.2 & 33.0 & 11.8 & 47.8 & 1.3 & 72.9 & 25.2 & 20.4 \\
\hline \multirow[t]{4}{*}{ CUNI } & D1 & 11.1 & 0.7 & 25.5 & 3.3 & 39.2 & 1.4 & 59.1 & 24.6 & 4.5 \\
\hline & D2 & 11.0 & 0.8 & 31.0 & 2.2 & 43.2 & 1.4 & 65.4 & 25.0 & 5.5 \\
\hline & D3 & 10.8 & 0.6 & 38.2 & 2.1 & 47.7 & 1.3 & 73.3 & 24.5 & 8.4 \\
\hline & D4 & 11.1 & 0.6 & 49.1 & 1.6 & 54.8 & 1.3 & 82.6 & 24.5 & 7.8 \\
\hline \multirow[t]{6}{*}{ FUNI } & El & 10.8 & 0.1 & 2.9 & 10.6 & 17.8 & 1.8 & 27.5 & 25.1 & 8.1 \\
\hline & E2 & 10.8 & 0.2 & 3.2 & 11.6 & 19.6 & 1.8 & 30.2 & 25.2 & 8.1 \\
\hline & E3 & 10.8 & 0.4 & 3.6 & 4.5 & 21.7 & 1.8 & 33.4 & 24.6 & 6.0 \\
\hline & E4 & 11.2 & 1.3 & 5.8 & 4.3 & 25.2 & 1.7 & 37.7 & 24.3 & 11.4 \\
\hline & E5 & 11.4 & 2.0 & 14.1 & 7.8 & 27.7 & 1.6 & 40.4 & 25.6 & 9.0 \\
\hline & E6 & 11.2 & 2.8 & 17.5 & 6.3 & 30.2 & 1.6 & 44.9 & 24.8 & 7.1 \\
\hline
\end{tabular}

that extended $25 \mathrm{~cm}$ in the flow direction and across the full width of the flume. All the transported sediment fell into the trap and was returned, with a small discharge of water, to the head of the channel by an air-driven diaphragm pump through a $2.5 \mathrm{~cm}$ (1 inch) tube. The efficiency of the trap was virtually $100 \%$.

Channel slope was adjustable by two coupled sets of screw jacks that tilted the flume about a pivot at its midpoint. The flow passed into the tailbox with no free overfall, so the volume of water in the flume determined the mean depth of flow. Uniform flow was maintained by adjusting the flume slope. Water discharge was determined from the calibrated bead loss in a straight section of the return pipe. Mean flow depth and water surface slope were determined from watersurface and bed surface elevations read with a point gage mounted on a cart that traversed rails parallel to the floor of the channel.

Sediment transport was sampled by passing the watersediment mixture in the sediment return system through a 20.3 $\mathrm{cm}(8$ inch) sieve that trapped the sediment and allowed the water to return to the head box through the diaphragm pump. This was achieved by closing a valve in the sediment return line between the trap and the pump and allowing the watersediment mixture to flow under gravity through a flexible tube into a large funnel that was itself connected to the sediment return system between the diversion valve and the pump. An open-air, gravity-driven sampling system was chosen to provide maximum flexibility in sampling methods and periods (sample intervals from $10 \mathrm{~s}$ to 4 hours were used during the experiments, depending on the transport rate, which itself varied by almost five orders of magnitude) and to allow con- venient removal of samples of the entire sediment load for size analysis. Sediment could also be returned to the recirculation system via the sample funnel, so that sampled sediment could be replaced.

\section{Sediment}

Essential to the experimental program was use of several sediment mixtures with different standard deviations of the grain size distribution. For direct comparison of transport rates of given fractions between different mixtures, the mean size of the principal mixtures used was held constant. This mean size was chosen (1) to allow at least a twofold variation in bed shear stress for all fractions before onset of suspension transport, (2) to ensure that the ratio of flow depth to grain size was no less than 12 for all fractions, and (3) to ensure that the mean flow Froude number did not exceed about 0.8 . The best compromise between these criteria and the availability of sediments led to the use of three sediments with a mean size in the $1.68-$ to $2.00-\mathrm{mm}$ fraction and standard deviations of 0.20 , 0.50 , and 0.99 when grain size is expressed in $\phi$ units. In the classification of Folk [1980], these sorting values correspond to very well-sorted, the well-sorted/moderately well-sorted boundary, and the moderately sorted/poorly sorted boundary. The sorting values were chosen to provide a transition between the relatively common and well understood unisize case and the existing fractional transport data, all for sediments with sorting values in excess of $1 \phi$. Cumulative size distributions for these mixtures are shown in Figure 2.

To effectively isolate the effect of mixture sorting on the initial motion of individual size fractions, the shape of the grain size distribution was held constant. A lognormal distri- 
TABLE 3. Equilibrium Bed Shear Stress and Transport Rates for MIT Experiments

\begin{tabular}{|c|c|c|c|c|c|c|c|c|}
\hline Mixture & Run & $\begin{array}{c}\text { Bed } \\
\text { Configuration }\end{array}$ & $\begin{array}{l}\mu_{*},{ }^{*} \\
\mathrm{~cm} / \mathrm{s}\end{array}$ & $\begin{array}{l}u_{*} s, \dagger \\
\mathrm{cm} / \mathrm{s}\end{array}$ & $\begin{array}{c}\text { Mean } \\
q_{b}, \\
\mathrm{~g} / \mathrm{ms}\end{array}$ & $\begin{array}{c}\text { Maximum } \\
q_{b}, \\
\mathrm{~g} / \mathrm{ms}\end{array}$ & $\begin{array}{c}\text { Minimum } \\
q_{b}, \\
\mathrm{~g} / \mathrm{ms}\end{array}$ & $\begin{array}{l}\text { Number of Bed } \\
\text { Forms Sampled }\end{array}$ \\
\hline \multirow[t]{6}{*}{ MUNI } & $\mathrm{A} 2$ & Plane & 2.99 & & 0.00185 & & & \\
\hline & A3 & Plane & 3.40 & & 0.359 & 0.44 & 0.30 & \\
\hline & A4 & $\begin{array}{l}\text { two-dimensional } \\
\text { large ripples }\end{array}$ & 3.64 & 3.70 & 3.19 & 4.93 & 1.95 & 2 \\
\hline & A5 & $\begin{array}{l}\text { two-dimensional } \\
\text { large ripples }\end{array}$ & 4.63 & 4.16 & 8.91 & 19.63 & 0.62 & 5 \\
\hline & A6 & $\begin{array}{l}\text { two-dimensional } \\
\text { large ripples }\end{array}$ & 4.96 & 4.57 & 23.0 & 85.3 & 0.426 & 11 \\
\hline & A7 & $\begin{array}{l}\text { two- to three- } \\
\text { dimensional } \\
\text { large ripples }\end{array}$ & 5.65 & 5.03 & 46.4 & 109.9 & 2.66 & 15 \\
\hline \multirow[t]{7}{*}{$1 / 2 \phi$} & B1 & plane & 3.02 & & 0.0144 & 0.0162 & 0.0126 & \\
\hline & B2 & $\begin{array}{l}\text { incipient two- } \\
\text { dimensional } \\
\text { large ripples }\end{array}$ & 3.09 & 2.95 & 0.037 & 0.0429 & 0.0304 & \\
\hline & B3 & $\begin{array}{l}\text { two-dimensional } \\
\text { large ripples }\end{array}$ & 3.41 & 3.43 & 1.12 & 2.85 & 0.493 & 3 \\
\hline & B4 & $\begin{array}{l}\text { two-dimensional } \\
\text { large ripples }\end{array}$ & 3.98 & 3.84 & 5.98 & 15.2 & 0.242 & 4 \\
\hline & B5 & $\begin{array}{l}\text { two-dimensional } \\
\text { large ripples }\end{array}$ & 4.60 & 4.22 & 13.7 & 41.4 & 2.34 & 11 \\
\hline & B6 & $\begin{array}{l}\text { two-dimensional } \\
\text { large ripples }\end{array}$ & 5.85 & 4.88 & 25.8 & 88.7 & 1.27 & 10 \\
\hline & B7 & $\begin{array}{l}\text { two- to three- } \\
\text { dimensional } \\
\text { large ripples }\end{array}$ & 7.08 & 6.12 & 97.0 & 238.0 & 16.5 & 23 \\
\hline \multirow[t]{5}{*}{$1 \phi$} & C1 & $\begin{array}{l}\text { plane } \\
\text { plane }\end{array}$ & 3.11 & & $\begin{array}{l}0.0231 \\
0.0330\end{array}$ & $\begin{array}{l}0.0238 \\
0.0424\end{array}$ & $\begin{array}{l}0.0224 \\
0.0195\end{array}$ & \\
\hline & $\mathrm{C} 3$ & $\begin{array}{l}\text { incipient two- } \\
\text { dimensional } \\
\text { large ripples }\end{array}$ & 4.19 & 3.63 & 2.32 & 5.63 & 0.595 & 3 \\
\hline & $\mathrm{C} 4$ & $\begin{array}{l}\text { two-dimensional } \\
\text { large ripples }\end{array}$ & 4.55 & 4.04 & 10.7 & 26.8 & 0.218 & 4 \\
\hline & C5 & $\begin{array}{l}\text { two-dimensional } \\
\text { large ripples }\end{array}$ & 5.18 & 4.66 & 29.7 & 87.2 & 0.45 & 10 \\
\hline & C6 & $\begin{array}{l}\text { two- to three- } \\
\text { dimensional } \\
\text { large ripples }\end{array}$ & 5.58 & 5.28 & 59.4 & 145.8 & 11.4 & 17 \\
\hline \multirow[t]{4}{*}{ CUNI } & D1 & plane & 4.97 & & 0.00335 & & & \\
\hline & D2 & plane & 5.47 & & 0.0345 & 0.0363 & 0.0323 & \\
\hline & D3 & plane & 6.03 & & 0.555 & 0.686 & 0.489 & \\
\hline & D4 & plane & 6.91 & & 9.55 & 13.1 & 7.5 & \\
\hline \multirow[t]{6}{*}{ FUNI } & E1 & plane & 1.57 & & 0.00247 & & & \\
\hline & E2 & plane & 1.62 & & 0.0245 & 0.0254 & 0.0237 & \\
\hline & E3 & plane & 1.72 & & 0.189 & 0.207 & 0.180 & \\
\hline & E4 & $\begin{array}{l}\text { two-dimensional } \\
\text { large ripples }\end{array}$ & 2.27 & 1.94 & 1.75 & 3.12 & 0.60 & 2 \\
\hline & E5 & $\begin{array}{l}\text { three-dimensional } \\
\text { large ripples }\end{array}$ & 3.77 & 2.33 & 4.12 & 26.8 & 1.09 & 3 \\
\hline & E6 & $\begin{array}{l}\text { three-dimensional } \\
\text { large ripples }\end{array}$ & 4.17 & 2.68 & 6.31 & 13.4 & 0.349 & 4 \\
\hline
\end{tabular}

*Sidewall-corrected total bed shear velocity (method of Vanoni and Brooks [1957]).

†Skin friction bed shear velocity (modification of Einstein [1950]).

bution was chosen because it is a well-defined distribution that approximates many natural sediments. Two other wellsorted sediments were used to provide a direct comparison between the well-sorted and poorly sorted cases for fractions in the fine, median, and coarse parts of the mixed-size sediment. These sediments had a mean size of 0.662 and $5.31 \mathrm{~mm}$ and are termed FUNI and CUNI, respectively. Although these two sediments were unimodal and fell mainly within three $1 / 4 \phi$ fractions, they did not have lognormal distributions because of the limited quantities of sediment available for processing and the lack of sufficient sieve grades to process the sediment more precisely (Figure 2).
Experimental control is more difficult to achieve for grain shape and density than for grain size. Although near-perfect control could have been attained using artificial sediments, it has been found that natural grains and spheres with the same size distribution have significantly different transport mechanics [Meland and Norrman, 1969]. Hence it seemed preferable to use natural sediment and exert as much control over grain shape and density as practical, primarily by careful selection of the source sediments. Because the same source sediments were used to blend each mixture, control of grain shape and density was virtually exact for comparisons among the three principal sediments of the transport rates of the same frac- 


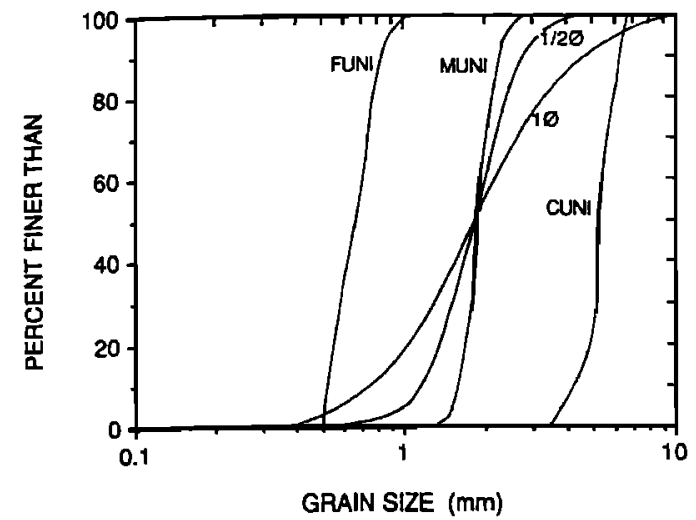

Fig. 2. Cumulative grain size distributions for the MIT sediment mixtures.

tions, and hence relative size expressed as $D_{i} / D_{m}$. The sediment consisted almost entirely of quartz and near-quartz density minerals, and the density used in transport computations is $2.65 \mathrm{~g} / \mathrm{cm}^{3}$. The middle portions of the sediment mixtures are slightly more angular (subangular versus subrounded) and of lower sphericity than either the coarse or fine well-sorted sediments or the tails of the sediment mixtures.

\section{Procedure}

The sediment bed was mixed and screeded to a plane bed 7 $\mathrm{cm}$ thick before each run. A precise mixing procedure was followed in which the sediment was first homogenized by hand in half-meter segments along the channel, then half the sediment in each segment was exhanged with that in other segments following a predetermined recipe, and finally the sediment was rehomogenized in each segment. The flume was then filled slowly with hot and cold water to achieve a temperature between $24^{\circ}$ and $26^{\circ} \mathrm{C}$. This temperature was maintained during runs by adding small volumes of hot or cold water to the flume; a constant water volume (and hence flow depth) was maintained with an overflow pipe in the tailbox.

Final flow and sediment transport measurements were made only after long-term steady transport became established. Equilibrium was judged by the absence of long-term variability in the flow properties (related to the development of a stable bed configuration) and size distribution of the transported sediment (related to the development of a stable grain size distribution on the bed surface). Small transport samples were taken periodically during the run to check for trends in the grain size distribution of the transport load. In practice, the grain size criterion was the controlling one. This, however, was primarily a function of practical limitations associated with determining the grain size distribution of the transport, rather than an inherent property of the transport, which appeared to reach a steady state on the same time scale as the bed forms.

When equilibrium was judged to have been reached, transport sampling was begun. This involved a combination of volumetric and mass samples. All of the transport was measured volumetrically by emptying the sample from the sampling sieve into a graduated cylinder. While a second sampling sieve was filling, the volume of sediment in the graduate was measured and the sample was returned to the recirculation system. During the sampling period all of the transported sediment was sampled except at very high transport rates, when we were not able to keep pace and could sample only 10 or 15 out of every $30 \mathrm{~s}$ of transport. The duration of the individual samples varied from 10 -s subsamples to a single 4-hour sample of a very small transport rate.

Some volumetric transport samples were not returned but saved to be dried, weighed, and sieved at $1 / 4 \phi$ intervals. The retained samples were replaced by equal volumes of sediment; usually, this replacement sediment was material sampled earlier in the same run or during the previous run, so its grain size distribution was not substantially different from the sampled sediment. If bed forms were present, an effort was made to measure the transport rates during the passage of at least three bed forms, although in two runs only two bed forms were sampled because of their very slow migration rates. Transport rates were computed only for whole numbers of bed forms. Total transport rates are given in Table 3. The mean grain size distribution of the transported load for each run was determined as a weighted mean for many samples taken over an individual bed form.

To avoid any significant impact on the sediment bed and transport rates, transport sampling (other than the small samples taken during the run) was conducted only at the end of a transport run. While the transport sampling was underway, the water surface elevation was read and the head loss in the return pipe was determined for later conversion to water discharge. After this sampling, the flume was drained and the bed (including a profile of the bed elevation along the flume centerline) was described.

\section{Bed Shear Stress}

Total bed shear stress was computed using the sidewall correction procedure of Vanoni and Brooks [1957]. The corrected values of total bed shear stress were consistently $20 \%$ greater than the total downslope component of the weight of the water ( $\rho g R S$, where $R$ is the hydraulic radius and $S$ the energy slope). Because bed forms were present in many runs, an estimate of the skin friction part of the total bed shear stress was necessary. Different models were evaluated in an attempt to derive the best estimate of the skin friction. Unfortunately, very limited means exist to evaluate the accuracy of skin friction estimates. The only sensitive test available to us was to evaluate the degree to which a given skin friction estimate decreases the observed scatter in the transport rate. In this regard the drag partition model of Einstein [1950] performed best. This model involves a fictitious flow hydraulic radius $\boldsymbol{R}^{\prime}$ that corresponds only to the skin friction and is computed iteratively from

$$
\frac{U}{\left(g R^{\prime} S\right)^{1 / 2}}=\frac{1}{\kappa} \ln \left(\frac{R^{\prime}}{2.718 z_{0}}\right)
$$

where $U$ is mean channel velocity, $\kappa$ is von Karman's constant, taken here to be 0.4 , and $z_{0}$ is roughness length characteristic of the sediment bed. A value of $z_{0}=D_{65} / 30$ was found to give a good approximation of the roughness of each sediment bed for flows with plane beds and little or no transport. An iterative procedure was used to increase this value of $z_{0}$ to account for the increase in apparent bed roughness due to the transport of sediment. These adjustments were minor, however, generally less than a factor of 2 , and because $z_{0}$ is present only in the log term of (4), the choice of $z_{0}$ had little effect on the estimated skin friction. Table 3 provides mean values of the sidewall-corrected shear velocity and the skin friction shear velocity. Further detail on the estimation of skin friction for our runs is given by Wilcock [1987].

To provide a good estimate of bed shear stress and transport rates near incipient motion, several runs with each sedi- 
TABLE 4. Mean Hydraulic and Transport Parameters for All Mixed-Size Transport Data

\begin{tabular}{|c|c|c|c|c|c|c|}
\hline Sediment & Reference & $\begin{array}{l}\text { Velocity, } \\
\mathrm{cm} / \mathrm{s}\end{array}$ & $\begin{array}{l}\text { Depth, } \\
\text { cm }\end{array}$ & $\begin{array}{l}\text { Slope, } \\
\times 10^{3}\end{array}$ & $\begin{array}{c}\text { Total Bed } \\
\text { Shear } \\
\text { Velocity, } \\
\mathrm{cm} / \mathrm{s}\end{array}$ & $\begin{array}{l}\text { Transport } \\
\text { Rates, g/ms }\end{array}$ \\
\hline MIT MUNI & Wilcock [1987] & $44.8-72.4$ & $11.4-12.8$ & $0.96-2.93$ & $2.99-5.65$ & $0.00185-46.4$ \\
\hline $\operatorname{MIT} 1 / 2 \phi$ & Wilcock [1987] & $43.6-79.4$ & $11.0-11.7$ & $1.00-4.92$ & $3.02-7.08$ & $0.0144-97.0$ \\
\hline MIT $1 \phi$ & Wilcock [1987] & $43.1-72.9$ & $10.9-11.2$ & $1.04-3.30$ & $3.11-5.58$ & $0.0231-59.4$ \\
\hline MIT FUNI & Wilcock [1987] & $27.5-14.9$ & $10.8-11.4$ & $0.29-1.75$ & $1.57-4.17$ & $0.00247-6.31$ \\
\hline MIT CUNI & Wilcock [1987] & $59.1-82.6$ & $10.8-11.1$ & $2.55-4.91$ & $4.97-6.91$ & $0.00335-9.55$ \\
\hline DAY A & Day $[1980 a]$ & $47.9-74.5$ & $10.7-16.9$ & $0.660-3.67$ & $3.20-6.11$ & $0.711-65.4$ \\
\hline DAY B & Day $[1980 a]$ & $44.1-72.2$ & $11.5-18.9$ & $0.445-2.99$ & $2.72-5.70$ & $0.134-90.3$ \\
\hline MISRI N1 & $\begin{array}{l}\text { Misri et al. } \\
\text { [1984] }\end{array}$ & $49.9-73.4$ & $5.9-11.7$ & $3.30-4.24$ & $4.26-6.69$ & $0.0642-68.5$ \\
\hline MISRI N2 & $\begin{array}{c}\text { Misri et al. } \\
{[1984]}\end{array}$ & $55.8-80.8$ & $7.8-13.5$ & $3.78-4.75$ & $5.30-76.1$ & $0.494-16.9$ \\
\hline MISRI N3 & $\begin{array}{l}\text { Misri et al. } \\
\text { [1984] }\end{array}$ & $58.7-82.6$ & $8.4-13.3$ & $3.45-4.31$ & $5.14-7.14$ & $0.627-29.7$ \\
\hline SAF & $\begin{array}{l}\text { Dhamotharan } \\
\text { et al. }[1980]\end{array}$ & $44.3-65.8$ & $4.0-6.7$ & $6.8-8.2$ & $5.58-6.46$ & $0.333-26.7$ \\
\hline Oak Creek & Milhous [1973] & $84.2-116.3$ & $27.4-44.5$ & $9.7-10.8$ & $16.3-20.8$ & $0.281-111.0$ \\
\hline
\end{tabular}

ment were clustered about initial-motion conditions. At least two runs with a plane bed, for which bed shear stress can be determined with much better accuracy than for those runs with bed forms, were conducted for each sediment. The transport rates of these plane bed runs fell near the reference value used to estimate the critical shear stress of each fraction.

\section{Other fractional Transport Data}

Fractional transport rates have been measured for a variety of different sediments in recent years. These data provide an opportunity to compare our results with other sediments and flows, although at the expense of control over other potentially important independent variables. Data examined here are from the laboratory experiments of Day [1980a], Misri et al. [1984], and Dhamotharan et al. [1980], and the Oak Creek field data of Milhous [1973]. These data are all for steady, uniform flow and involve bed preparation and run times (for the laboratory data) and sampling methods of a nature that permit reasonable estimates of the accuracy of the transport rates of individual fractions in the mixtures. The mean hydraulic parameters for these studies, as well as for ours, are given in Table 4. Cumulative plots of the bed grain size distributions are given in Figure 3 . In addition to a wide range in mean size and sorting, the size distributions of these sediments show a marked variation in size distribution shape. Three sediments are distinctly bimodal. These are (with the location of the modes expressed as $\left.D_{i} / D_{m}\right)$ Day bed $A(0.30,4.0)$, Day bed $B(0.30,2.4)$, and Dhamotharan et al. $(0.84 ; 3.3)$. Sediments $\mathrm{N} 1$ and N3 of Misri et al. are close to lognormal, and sediment N2 has a nearly rectangular distribution. The Oak Creek bed size distribution has a very long fine tail: $D_{s} / D_{50}=$ $6\left(D_{95} / D_{50}\right)$.

\section{INITIAL MOTION RESULTS}

\section{Methodology}

The initial-motion conditions, or critical shear stress $\tau_{c i}$, of individual fractions in a mixed-size sediment have typically been determined using one of two different classes of methods. The first method involves estimating $\tau_{c i}$ as the bed shear stress that produces a small transport rate for each fraction. Transport rates of individual fractions are measured for a number of flows and the shear stress that corresponds to a small refer- ence transport rate is determined from a fitted relation between dimensionless shear stress and dimensionless transport rate for each fraction [Parker et al., 1982; Day, 1980b]. The second method involves determining the largest clast in a sediment mixture that is moved by a given bed shear stress. The largest grain displaced may be measured directly using the largest clast found in a transport sample [Andrews, 1983; Carling, 1983] or measured visually by observing the largest grain moving over an area of the bed [Hammond et al., 1984]. The largest mobile grain is assumed to represent initialmotion conditions if coarser grains are available in the bed. A companion paper [Wilcock, this issue] describes and compares these methods in some detail. In this paper, the reference transport method is used because all sizes were found to be in transport even at the lowest transport rates. Under these conditions, the largest-grain method provides no information on $\tau_{c b}$ for any fraction other than the coarsest and may not be used.

A number of different reference transport criteria have been suggested. Parker et al. [1982] (hereafter referred to as PKM) define the reference transport rate in terms of a constant value of the fractional transport parameter $W_{i}^{*}$

$$
W_{i}^{*}=\frac{(s-1) g q_{b i}}{f_{i}\left(u_{*}\right)^{3}}
$$

where $q_{b i}$ is the transport rate of fraction $i$ in terms of volume transport per unit width and time, and $f_{i}$ is the proportion of fraction $i$ in the bed sediment. The PKM reference transport rate is $W_{i}^{*}=0.002$. Day $[1980 b]$ defines the reference transport rate using the Ackers and White [1973] (hereafter referred to as $\mathrm{AW}$ ) transport model, in which the transport parameter Ggr can be defined as

$$
G g r=\frac{q_{b}}{V D}\left[\frac{u_{*}}{V}\right]^{n}
$$

and $V$ is mean flow velocity, $D$ is a representative grain size and the exponent $n$ varies with a dimensionless measure of grain size from 1.0 for silt-sized grains to 0.0 for grains coarser than about $2.0-3.0 \mathrm{~mm}$. The AW reference transport rate is Ggr $=10^{4}$.

Values of the reference transport estimate of the critical shear stress $\tau_{r i}{ }^{*}$ were computed using both reference transport 


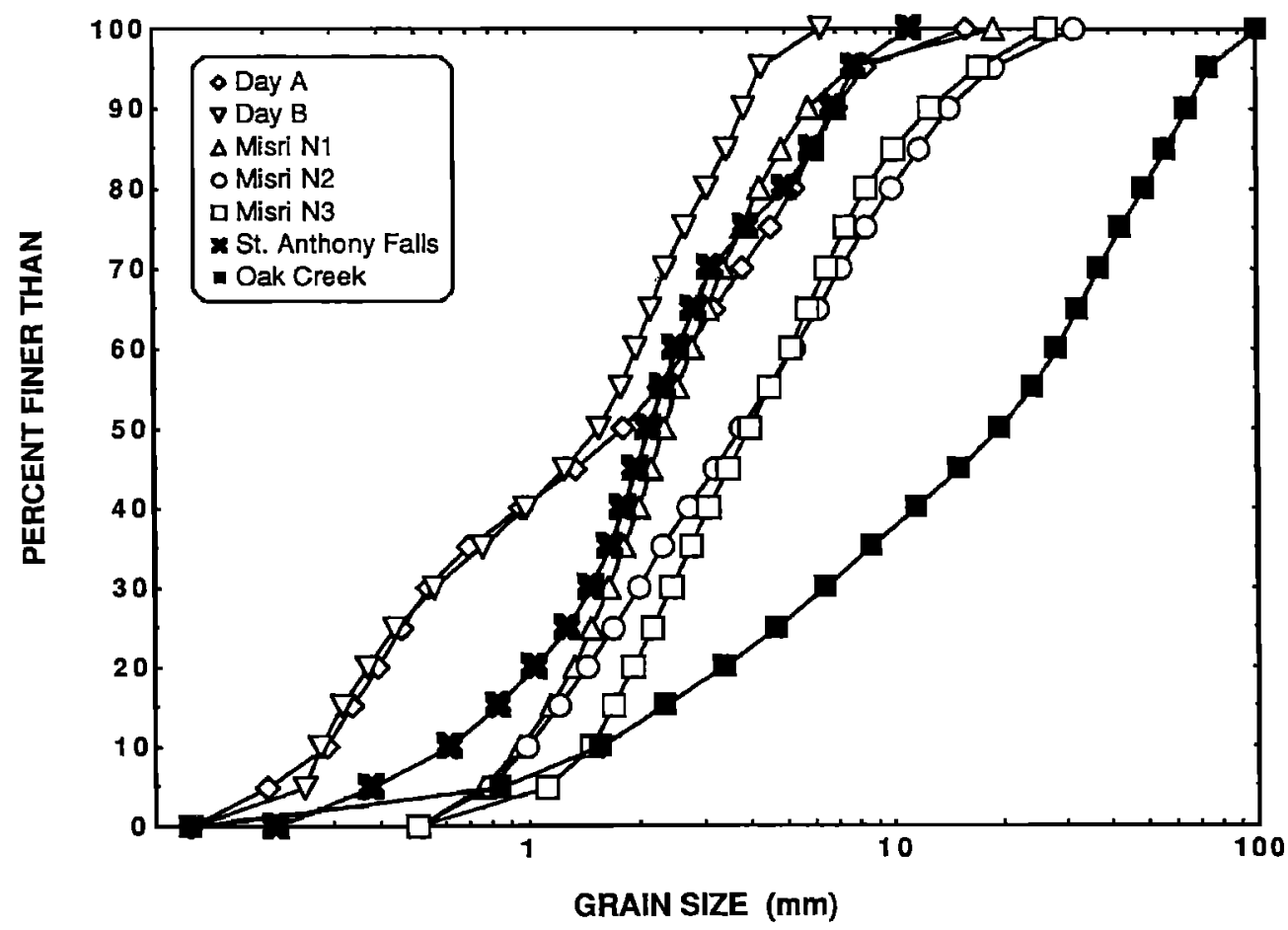

Fig. 3. Cumulative grain size distributions for previously published mixed-size sediment transport data.

criteria, although the discussion here will focus primarily on the PKM reference transport criterion. This is because the $\tau_{r i}{ }^{*}$ values measured at constant $W^{*}$ are undistorted with respect to grain size ( $D$ is not found in the transport parameter $W_{i}^{*}$ ), a considerable convenience when comparing the reference shear stresses for different sizes in a mixture. The PKM criterion is also of interest because it was used with the Oak Creek data to produce the distinctive and important result that all grains begin moving at nearly the same bed shear stress [Parker et al., 1982]. Initial-motion results computed with the AW reference transport criteria are directly convertible from the PKM values of $\tau_{r i}{ }^{*}$; the results computed with the AW method will be discussed in comparison with the PKM results.

\section{Fitting Technique}

Although conceptually simple, computation of the reference shear stress for individual fractions requires a number of choices concerning the appropriate techniques for fitting the data. Not only must a reference transport criterion be chosen, but also an appropriate curve of transport rate versus shear stress must be fitted to the data, and the method of fitting the curve to the data must be chosen.

The form of the relation between transport rate and shear stress fitted to the data was determined largely by the trend of the data. The fractional transport rates of every third fraction in the MIT $1 \phi$ mixture are presented in Figure 4 in terms of $W_{1}^{*}$ and $\tau_{i}^{*}$. The separation of the data along the $\tau_{i}^{*}$ axis results solely from the presence of the fraction size in the denominator of $\tau_{i}^{*}$. Because grain size is not present in $W_{i}^{*}$, the dimensional transport rates of the different fractions may be seen to be comparable at the same level of $\tau_{0}$. This observation, combined with the similarity in form of the $W_{i}^{*}-\tau_{i}^{*}$ relations for each fraction, leads directly to the conclusion that all fractions begin moving at about the same bed shear stress. Hence the reference transport procedure is essentially a means of documenting this observation consistently. The data in
Figure 4 show a strong concave-downward trend. To obtain a good fit to these data, and hence a good estimate of the reference shear stress, a similarly curved transport function is needed. The relation chosen is a power approximation of the Einstein [1950] bed load function at low stresses derived by Parker [1979]

$$
W_{i}^{*}=11.2\left(1-\frac{0.8531 \tau_{r i}^{*}}{\tau_{i}^{*}}\right)^{4.5}
$$

This curve, and the reference transport criterion $W_{i}^{*}=0.002$, are shown in Figure 4. Other transport functions could have been chosen, although they would not have produced significant differences in the measured $\tau_{p i}{ }^{*}$ because the transport function was primarily used to simply extrapolate or interpo-

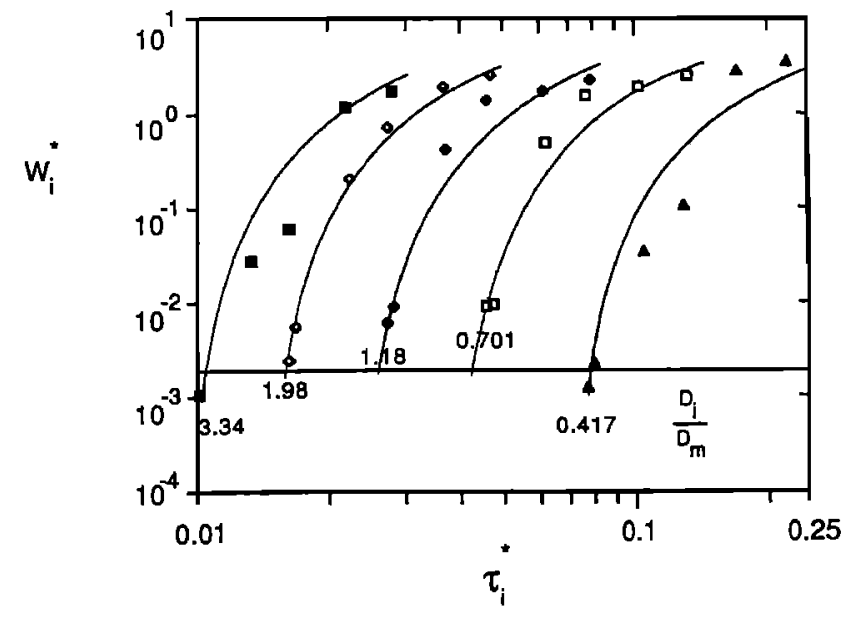

Fig. 4. Fractional transport rates for the $1 \phi$ MIT sediment mixture (every third fraction shown). Reference transport rate $W_{1}^{*}=$ 0.002 is marked; also shown is the curve from Parker [1979] used to determine $\tau_{r 1}{ }^{*}$. Note that the abscissa scale is expanded more than 4 times with respect to the ordinate scale. 
late to $W_{r}^{*}$ from points near $W_{r}^{*}$, and because transport functions that provide a reasonable fit to the data have about the same slope near $W_{r}^{*}$.

Placement of the curve was determined largely from the data points near $W_{r}^{*}$. The curve was fitted by eye as a convenient means of giving added weight to points near the reference transport value. Nonlinear least squares fitting was initially used, but did not always give the best visual match to the data because it was overly influenced by small errors in the shear stress term for points near initial motion, where the transport function is very steep. The fitting was done as follows. If two or more points fell close to $W_{r}^{*}$ (within approximately a factor of 2), the curve was placed so as to match those points most closely. When only one point was found near $W_{r}^{*}$, this point was still given added weight, but placement was also influenced by the fit of the curve to the rest of the data points for that fraction. In these cases, and when no points were close to $W_{r}^{*}$, the importance of using a curved line to fit the data was obvious, because it gives an extrapolation to $W_{r}^{*}$ that is more reasonable than the loglinear extrapolations used previously [e.g., Parker et al., 1982]. To preserve the grain size independence of the fitting procedure, the transport curve was translated only parallel to the $\tau_{r}^{*}$ axis.

Because the curve fitting was to some extent subjective, a conservative estimate of the error in the measured values of $\tau_{r i}{ }^{*}$ is necessary. This error was estimated by reading the values of $\tau_{r}^{*}$ when the curve was placed as far as possible to the right and left of the measured $\tau_{r i}{ }^{*}$ while still giving a reasonable fit to at least some of the transport data for each fraction. This error estimate is analogous to a confidence interval for an estimated intercept in that the true $\tau_{r i}{ }^{*}$ is highly likely to fall within the error bounds, but it is different from a standard confidence interval in that (1) it is fitted by eye, (2) it has only a subjective dependence on the number of data points fitted, and (3) the measured data point generally does not fall at the midpoint of the error bounds. The fitted $\tau_{r i}{ }^{*}$ and the associated error bounds are given in Table 5 .

The $\tau_{r i}{ }^{*}$ fitted to our data generally involved at least two points near $W_{r i}^{*}$ because we clustered some runs for each sediment near initial-motion conditions. Although these points determined the placement of the curve, the fit of the curve to our data at higher transport rates was also usually very good. The scatter evident in Figure 4 is largely the result of using extremely different scales for the $\log$ axes, so the separation of the data points could be distinguished. The fit of the transport function to the other data was in some cases less accurate than the fit to our data, owing to the absence of points near $W_{r i}{ }^{*}$ (DAY A), data scatter (MISRI N1), or trends that were significantly different from the fitting curve (DAY A). Although cases where the fit was poor increased the error in estimating $\tau_{r i}{ }^{*}$ for any given fraction (which is reflected in the error bounds of Table 5), the poor fit does not lead to a similar uncertainty in the variation of $\tau_{r i}{ }^{*}$ from fraction to fraction, which is more important for understanding the relative-size effect on $\tau_{r i}{ }^{*}$. This is because plots of $W_{i}^{*}$ against $\tau_{i}^{*}$ were in most cases clearly translated from fraction to fraction with little change in the form of the scatter. Thus the transport function could be fitted consistently to each fraction, so that the variation of $\tau_{r i}{ }^{*}$ with relative size is of a higher precision than that with which individual values of $\tau_{r i}^{*}$ can be determined.

\section{Relative Size Effect}

One of the primary goals of this work is to determine whether a single relative-size parameter, like $D_{i} / D_{s 0}$, is sufficient to describe the effect of relative grain size on $\tau_{r i}{ }^{*}$. By

TABLE 5. Values of $\tau_{r i}^{*}$ Fitted by PKM Reference Transport Criterion

\begin{tabular}{llr}
\hline$D_{i}$ & \multicolumn{1}{c}{$\tau_{r i}{ }^{*}$} & Error Bounds \\
\hline & \multicolumn{1}{c}{$M I T I \phi$} & \\
0.595 & 0.105 & $0.100-0.0129$ \\
0.771 & 0.0794 & $0.0708-0.0871$ \\
0.917 & 0.0631 & $0.0575-0.0661$ \\
1.09 & 0.0501 & $0.0457-0.0525$ \\
1.30 & 0.0417 & $0.0389-0.0437$ \\
1.54 & 0.0363 & $0.0324-0.0372$ \\
1.83 & 0.0309 & $0.0275-0.0309$ \\
2.18 & 0.0257 & $0.0240-0.0269$ \\
2.59 & 0.0224 & $0.0200-0.0229$ \\
3.08 & 0.0191 & $0.0170-0.0191$ \\
3.67 & 0.0158 & $0.0151-0.0162$ \\
4.36 & 0.0141 & $0.0138-0.0148$ \\
5.19 & 0.0123 & $0.0117-0.0132$ \\
6.17 & 0.0105 & $0.0105-0.0123$
\end{tabular}

\section{MIT I/2 $\phi$}

0.0794

0.0603

0.0501

0.0427

0.0355

0.0295

0.0251

0.0209

0.0178

$0.0759-0.0955$ $0.0589-0.0724$ $0.0479-0.056$ ? 0.0398-0.0479 $0.0331-0.0380$ $0.0263-0.0316$ $0.0234-0.0269$ $0.0200-0.0229$ $0.0174-0.0191$

0.0275

0.0229

0.0191

0.771

0.0166

$0.0240-0.0275$ $0.0186-0.0229$ $0.0162-0.0195$ $0.0138-0.0170$

4.36

5.19

6.17

0.288

0.336

0.393

0.455

0.537

0.694

0.971

1.36

1.82

2.29

2.74

3.25

3.87

4.59

5.32

6.05

6.95

0.275

0.318

0.369

0.438

0.559

0.758

0.997

1.27

1.57

1.81

1.99

2.17

2.40

2.72

3.09

\section{MIT CUNI}

0.0457

0.0380

0.0316

DAYA

0.162

0.107

0.0955

0.0813

0.0617

0.0490

0.0372

0.0324

0.0263

0.0229

0.0191

0.0170

0.0151

0.0138

0.0120

0.0110

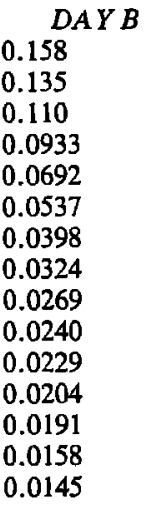

$0.0437-0.0501$ $0.0363-0.0398$ $0.0302-0.0339$

$0.155-0.170$

$0.129-0.158$

$0.107-0.145$

$0.0955-0.166$

$0.0813-0.123$

$0.0617-0.091$ ?

$0.0490-0.0813$

$0.0372-0.0550$

$0.0309-0.0389$

$0.0263-0.0347$

$0.0219-0.0275$

$0.0186-0.0219$

$0.0162-0.0191$

$0.0145-0.0186$

$0.0129-0.0166$

$0.0117-0.0141$

$0.0105-0.0132$

$0.151-0.174$

$0.135-0.151$

$0.110-0.135$

$0.0933-0.107$

$0.0692-0.0851$

$0.0490-0.0575$

$0.0380-0.0417$

$0.0309-0.0363$

$0.0263-0.0324$

$0.0240-0.0295$

$0.0229-0.0295$

$0.0200-0.0240$

$0.0178-0.0214$

$0.0148-0.019$

$0.0129-0.0182$ 
TABLE 5. (continued)

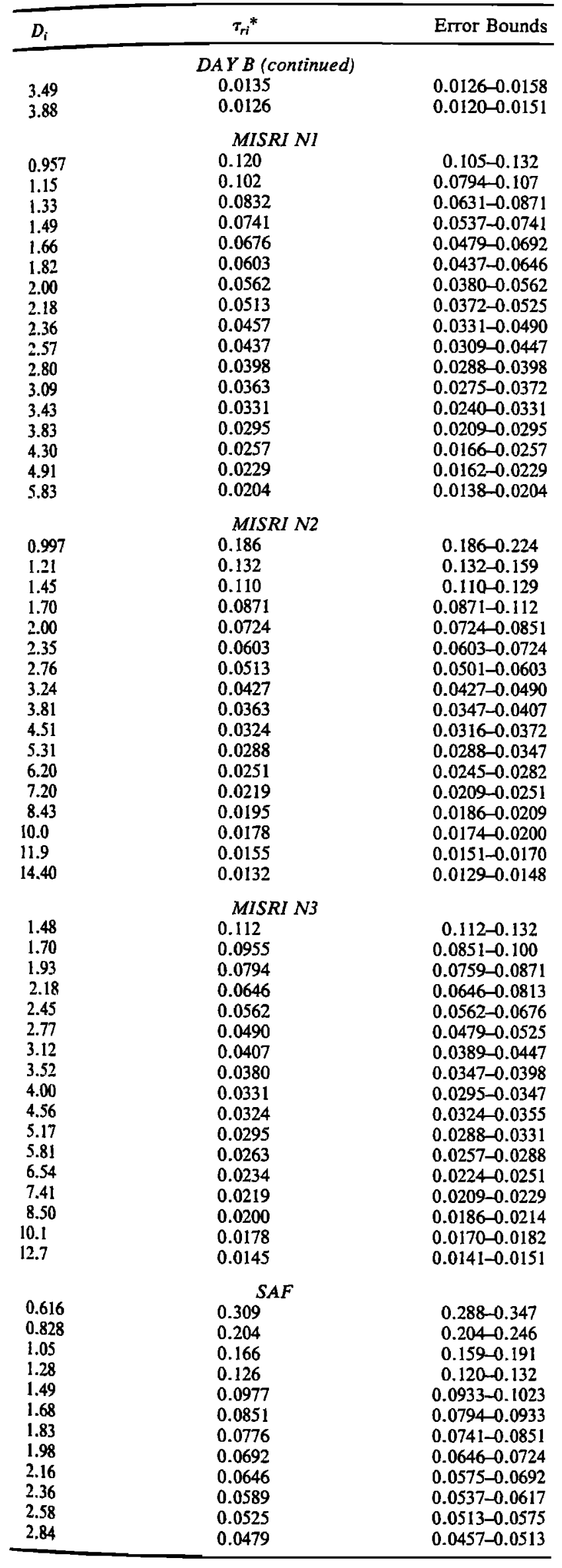

TABLE 5. (continued)

\begin{tabular}{rll}
\hline$D_{i}$ & \multicolumn{1}{c}{$\tau_{r i}{ }^{*}$} & Error Bounds \\
\hline & SAF (continued) & \\
3.19 & 0.0447 & $0.0417-0.0490$ \\
3.96 & 0.0355 & $0.0316-0.0380$ \\
5.07 & 0.0288 & $0.0269-0.0295$ \\
6.04 & 0.0240 & $0.0234-0.0257$ \\
6.94 & 0.0219 & $0.0200-0.0229$ \\
& & \\
1.57 & Oak Creek & \\
2.37 & 0.575 & $0.575-0.631$ \\
3.40 & 0.380 & $0.380-0.427$ \\
4.75 & 0.282 & $0.269-0.302$ \\
6.48 & 0.200 & $0.195-0.214$ \\
8.72 & 0.148 & $0.145-0.158$ \\
11.5 & 0.107 & $0.100-0.117$ \\
15.1 & 0.0832 & $0.0794-0.0891$ \\
19.5 & 0.0646 & $0.0589-0.0692$ \\
24.3 & 0.0490 & $0.0447-0.0525$ \\
28.4 & 0.0389 & $0.0372-0.0417$ \\
32.5 & 0.0339 & $0.0316-0.0380$ \\
37.1 & 0.0302 & $0.0288-0.0331$ \\
42.8 & 0.0257 & $0.0251-0.0288$ \\
49.3 & 0.0234 & $0.0214-0.0251$ \\
56.6 & 0.0200 & $0.0186-0.0209$ \\
64.6 & 0.0170 & $0.0170-0.0186$ \\
74.4 & 0.0158 & $0.0151-0.0170$ \\
\hline & 0.0141 & $0.0126-0.0148$ \\
\hline & &
\end{tabular}

holding the mean size and size distribution shape constant in our experiments, as well as flow depth and water temperature, we isolated the effect on $\tau_{p i}{ }^{*}$ of percent finer than (or mixture sorting) for particular fractions (values of $D_{i} / D_{50}$ ). The fitted $\tau_{r i}{ }^{*}$ for our data are plotted against $D_{i} / D_{50}$ in Figure 5 . The error bounds are shown as cross-hatching in the figure; the error bounds for the $1 \phi$ and $1 / 2 \phi$ mixtures essentially overlap and are shown as only one pattern representing the outermost error bounds for either mixture. The coefficients and exponents of straight lines fitted to the data in Figure 5 are given in Table 6.

The data in Figure 5 suggest clearly that only a single relative-size parameter, in this case $D_{i} / D_{50}$, is needed to characterize the relative-size effect on $\tau_{r i}{ }^{*}$. This may be illustrated in two complementary ways. First, the $\tau_{r i}{ }^{*}$ for the same fractions (and hence the same grain sizes) in the $1 / 2 \phi$ and $1 \phi$ mixtures may be compared. Only the percentile position within the mixture varies between these fractions, yet the $\tau_{r i}{ }^{*}$ values for each $D_{i} / D_{50}$ are nearly identical. Alternatively, it may be seen that the $\tau_{r i}{ }^{*}-D_{j} / D_{30}$ trends for all four sediments in Figure 5 are very similar, even though mixture sorting varies from $0.19 \phi$ to $0.99 \phi$. The trends for these sediments fall in the narrow range of -0.97 to -1.06 . Only the trend of the CUNI mixture $(-1.06)$ is significantly different from the other mixtures at the $95 \%$ level. Both views of the problem provide a well-controlled demonstration that when the effect of $D_{i} / D_{50}$ on $\tau_{r i}{ }^{*}$ is taken into account, the mixture sorting (or percent finer than) does not affect $\tau_{r i}{ }^{*}$ appreciably.

The data in Figure 5 also show, for the first time, that consistent initial-motion relations appear to hold for sediments with a broad range of grain sizes and for sediments very close to unisize. Such a result is necessary for any generally valid model for initial motion of mixed-size sediments, which must include the limiting case of unisize sediment. As we will show later, the actual $\tau_{r i}{ }^{*}$ for our well-sorted sediments fall within the range one would expect for unisize sediments. Both the consistency of $\tau_{r i}{ }^{*}-D_{i} / D_{50}$ relations over a wide range of 


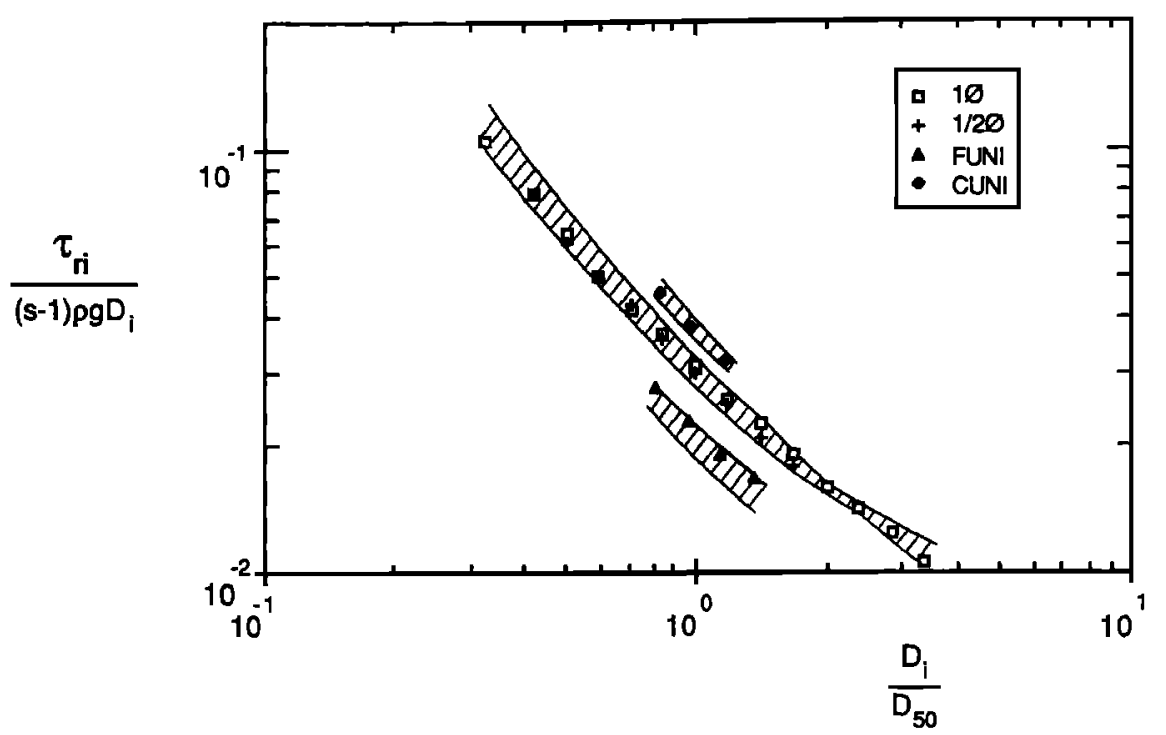

Fig. 5. The $\tau_{r 1}{ }^{*}$ as a function of $D_{i} / D_{50}$ for the MIT sediments.

sorting and the fact that the $\tau_{r i}{ }^{*}$ converge to reasonable unisize critical shear stresses lend credence to our specific $\tau_{\mathbf{r i}}{ }^{*}$ results and the methodology used to compute them.

Figure 6 presents $\tau_{r i}{ }^{*}$ against $D_{t} / D_{50}$ for the other, previously published, transport data. Error bounds for these data (given in Table 5 but omitted from Figure 6 for clarity) tend to be of the same order as those for our sediments, but are slightly larger. The coefficients and exponents of straight lines fitted to the data in Figure 6 are given in Table 6. Again, the slopes of the $\tau_{r i}^{*}-D_{i} / D_{50}$ relations fall within a fairly small range of -0.81 to -1.09 . This result is striking, because the experimental control behind our data in Figure 5 is lacking in Figure 6. Although the mixture sorting of the sediments in Figures 5 and 6 varies from $0.19 \phi$ to $2.1 \phi$, there is no consistent trend between mixture sorting and the form of the $\tau_{r i}{ }^{*}-D_{i} / D_{s 0}$ relations. This provides more general empirical support for our controlled experimental result that once the effect of $D_{i} / D_{50}$ is accounted for, mixture sorting (or percent finer than) does not contribute significantly to variation in $\tau_{r i}^{*}$.

The variation in $\tau_{r i}^{*}$ can also be examined with respect to the percentile position of the individual fractions. When a mixture is close to unisize, $\tau_{r i}{ }^{*}$ should not depend on $P$, percent finer than, because all fractions are nearly the same size. Hence a plot of $\tau_{r}{ }^{*}$ against $P$ should approach a limiting

TABLE 6. Least Squares Fit to $\tau_{r i}{ }^{*}=\alpha\left(D_{i} / D_{50}\right)^{\beta}$

\begin{tabular}{lccc}
\hline Sediment & & & $\begin{array}{c}\beta \\
\text { Error } \\
\text { at } 95 \%\end{array}$ \\
\hline MIT 1/2 $\phi$ & 0 & $\beta$ & 0.0158 \\
MIT 1 $\phi$ & 0.0301 & -1.006 & 0.0447 \\
MIT FUNI & 0.0356 & -0.970 & 0.1986 \\
MIT CUNI & 0.0226 & -0.984 & 0.0150 \\
DAY A & 0.0371 & -1.064 & 0.0286 \\
DAY B & 0.0368 & -0.809 & 0.0292 \\
MISRI N1 & 0.0368 & -0.953 & 0.0255 \\
MISRI N2 & 0.0475 & -0.997 & 0.0653 \\
MISRI N3 & 0.0415 & -0.953 & 0.0806 \\
SAF & 0.0371 & -0.920 & 0.0610 \\
Oak Creek & 0.0708 & -1.091 & 0.0093 \\
\hline
\end{tabular}

slope of zero as sorting approaches unisize, providing a benchmark to evaluate the reasonableness of our measured $\tau_{r i}{ }^{*}$. Plots of $\tau_{r i}^{*}$ against $P$ also have the advantage of not shrinking to a single point as the mixture approaches unisize, a considerable advantage when the variation of $\tau_{r i}{ }^{*}$ with relative grain size is of interest. Figure $7, \tau_{r i}{ }^{*}$ as a function of $P$ for our data, clearly shows the trends to decrease in slope as sorting approaches unisize. This change in slope is illustrated in Figure 8, which presents the slopes $b_{1}$ of straight lines fitted to the central parts of $\tau_{r i}{ }^{*}-P$ relations for all the sediment mixtures. The slopes, graphed as a function of mixture sorting. show a trend that is remarkably consistent over the entire range of sorting and approaches the appropriate limiting value of zero at unisize. Although Figure 7 shows no new physical information beyond Figure 5 , it does establish that the measured $\tau_{r i}{ }^{*}$ values conform to a physically reasonable limit.

Although only one of $D_{i} / D_{50}$ or $P$ is sufficient to describe the effect of relative size on $\tau_{r i}{ }^{*}$ for sediments investigated here, $D_{i} / D_{50}$ appears to be preferable for practical use because $\tau_{r i}{ }^{*}-D_{i} / D_{50}$ relations are simpler in form and allow physical conclusions on initial motion to be drawn directly from the data.

The lack of variation in the $\tau_{r i}{ }^{*}-D_{i} / D_{50}$ relations of Figures 5 and 6 is striking because, in addition to a broad variation in the mean size, sorting, and shape of the mixture size distributions, other potentially important independent variables, like relative depth and grain Reynolds number, show considerable variation both within each mixture and from mixture to mixture. Figure 9 presents the $\tau_{r i}{ }^{*}$ for all mixtures plotted against $S^{*}\left(=\left[D_{i}{ }^{3}(s-1) g\right]^{1 / 2} / v\right)$, a convenient surrogate for grain Reynolds number. Also shown is the classic Shields curve for incipient motion of unisize sediments (Shields [1936]; version of Miller et al. [1977] plotted here). Even though the sediment mixtures are broadly distributed across the figure and extend to varying degrees into the transitionally rough and smooth turbulent ranges, the form of the $\tau_{r i}{ }^{*}$ plots (in this case, as functions of $D_{i}^{-3 / 2}$ ) are remarkably consistent. The consistent trends in Figures 5, 6, and 9 are an important result that is independent of methodological problems. When the best available data on mixed-size sediment transport are combined into the same reference-transport analysis, there is virtually no variation in the relative-size effect on $\tau_{r i}{ }^{*}$, even 


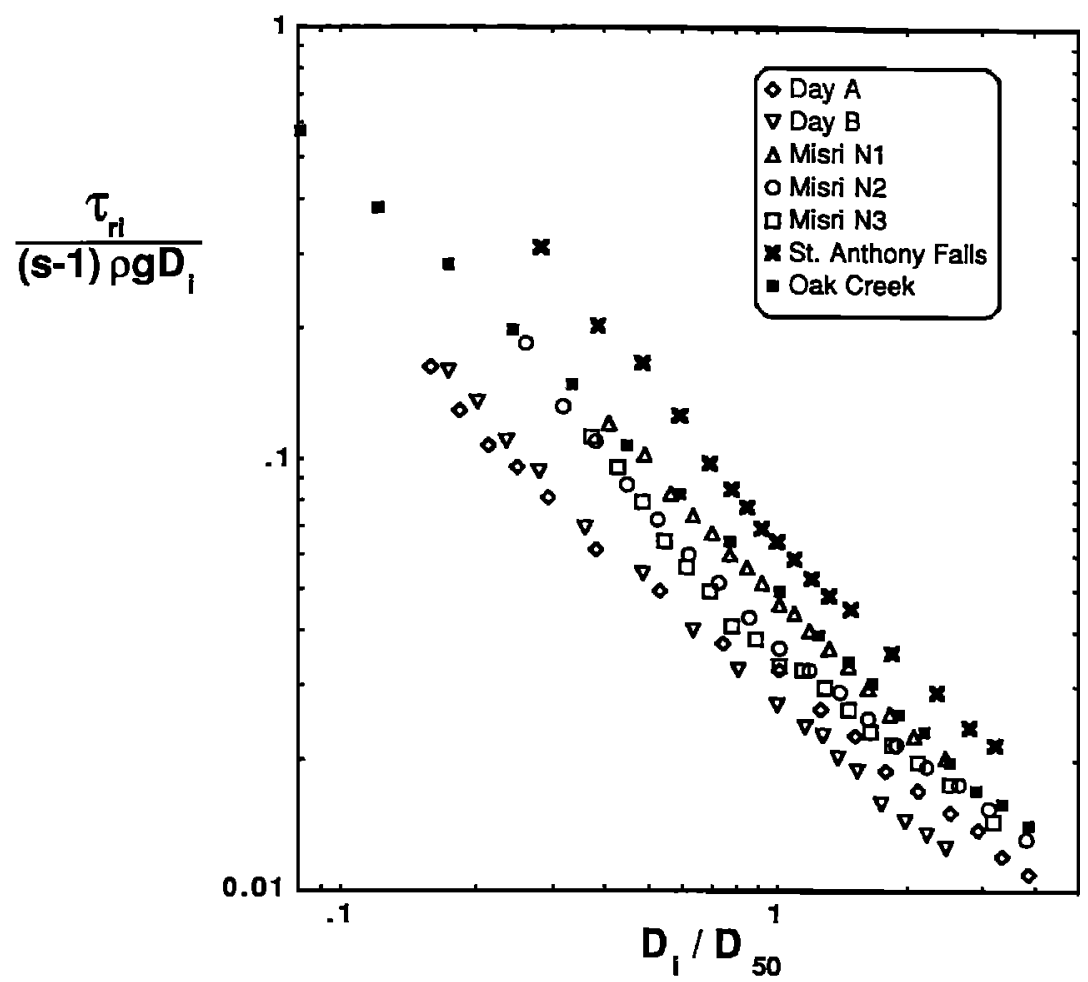

Fig. 6. The $\tau_{r i}^{*}$ as a function of $D_{\downarrow} / D_{50}$ for other sediments.

though flow and sediment conditions vary from mixture to mixture. Although there are far from enough data to support an absolute and general conclusion, the consistency evident in these figures suggests that the relative-size effect on the initial motion of individual fractions is dominant and consistent for a broad range of flows and sediments.

\section{Equal Mobility}

An additional important result is that the slopes of the $\tau_{r t}{ }^{*}-D_{i} / D_{50}$ relations all fall in the vicinity of the special value -1.0 , although to some extent this depends on the use of the PKM reference transport criterion. The AW reference trans- port criterion produces somewhat different relations to be discussed in a later section of this paper. Using the PKM reference transport criterion, six of the eleven sediments have slopes not significantly different from -1.0 at a $95 \%$ confidence level. Of the remaining five, two have slopes actually smaller than -1.0 . Of the three that have slopes greater than -1.0 , only sediment A of Day [1980a] has a value of $\beta$ considerably different from -1.0 (Table 6 ). This is also the only sediment for which no points fall close to $W_{r}^{*}$, making it the least certain of the sets of $\tau_{r i}^{*}$ values. $A \tau_{r i}^{*}-D_{i} / D_{\text {so }}$ slope of -1.0 means that all fractions in the mixture cross the reference transport level at the same dimensional bed shear stress

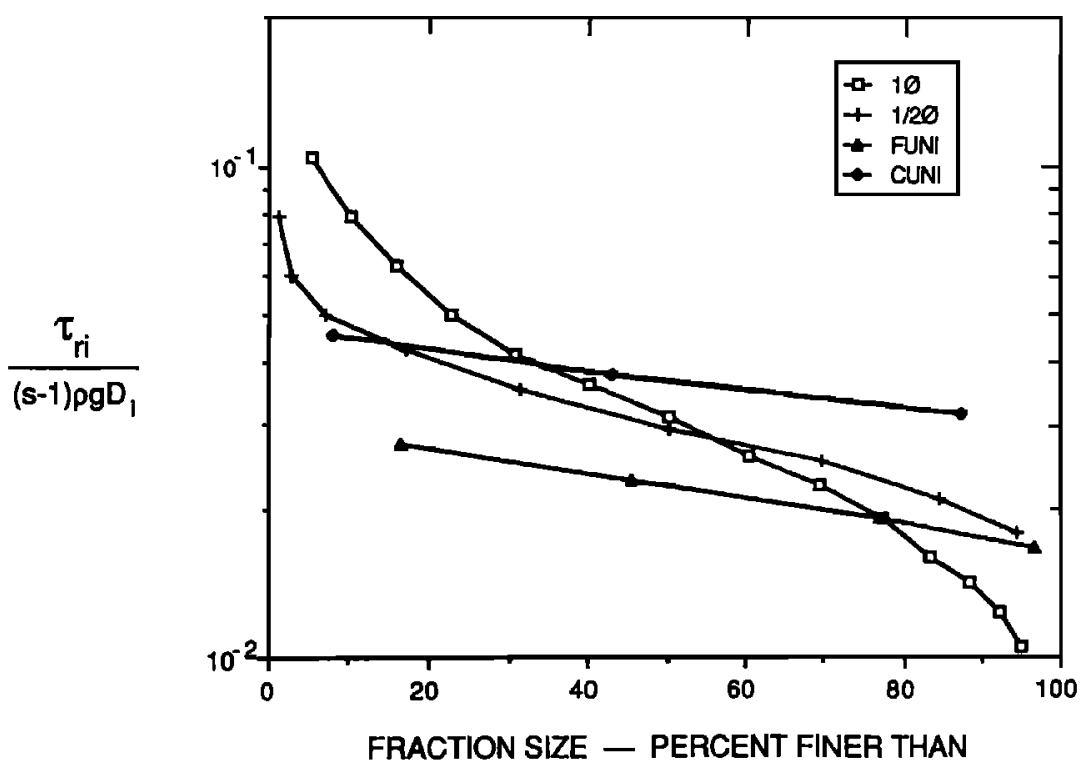

Fig. 7. The $\tau_{r i}{ }^{*}$ as a function of percent finer than for MIT sediments. 


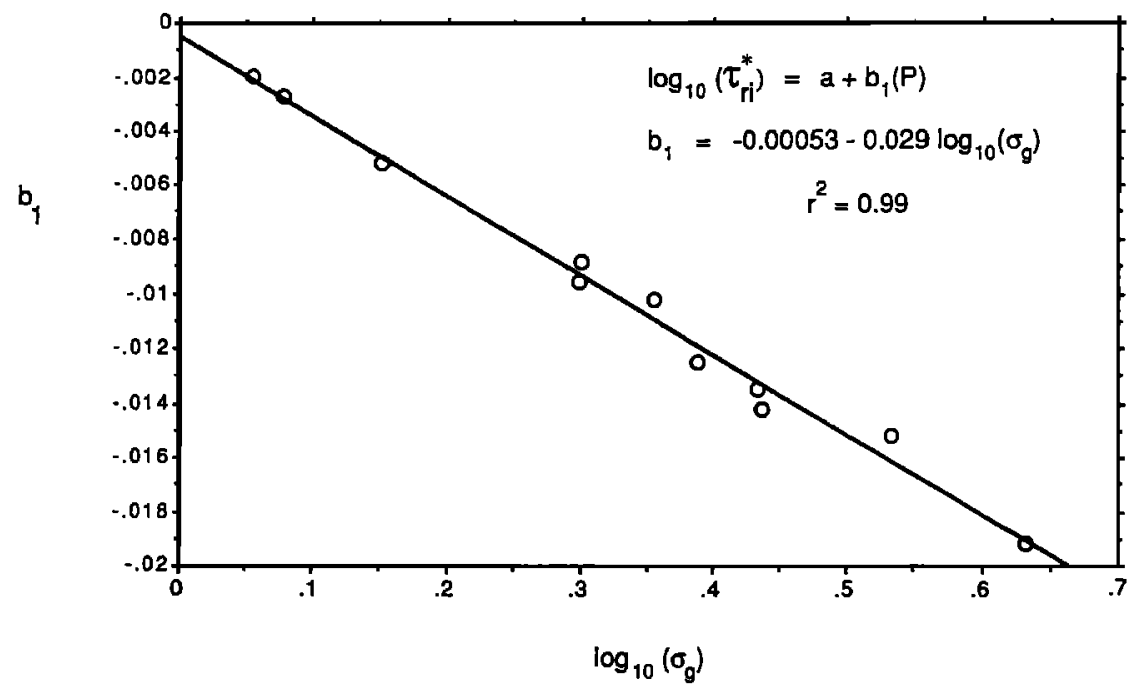

Fig. 8. The $\tau_{r i}{ }^{*}-P$ slopes as a function of mixture sorting.

$\tau_{0}$. If the reference transport rate is analogous to the critical shear stress for each fraction, a slope of -1.0 signifies that all fractions begin moving, at least, at any appreciable transport rate, at the same dimensional bed shear stress. This is the result PKM found using their reference transport criterion on the Oak Creek data, which they termed the equal mobility hypothesis. The trends in Figures 5 and 6 suggest that this result may not be particular to that stream, but may have a broader application for equilibrium transport by steady, uniform flows.

The cause of the size independence of $\tau_{r i}$ in the data examined here is worth considering. Parker and Klingeman [1982] point out that equal mobility is the natural state toward which equilibrium transporting systems evolve, although this is completely true only for transporting systems in which the mixedsize transport rate is imposed on the system (e.g., sediment feed flumes). In these cases, an equilibrium transport state requires that the slope and grain size distribution of the bed surface adjust so that the transport rate of each fraction equals that imposed on the system. All of the data used here, how. ever, with the exception of Oak Creek, involved recirculation of the transported sediment. We see no reason why all fractions should be equally transportable in a recirculating, equilibrium transport system. For example, some fractions could simply be immobile at bed shear stresses for which other fractions are in motion. As a consequence, equal mobility in a recirculating system must be assumed to be an empirical result that happens to be the same as in systems where the fractional transport rates are imposed on the system.

Regardless of system constraints, equal mobility conditions in both recirculating and feed systems are produced by two mechanisms. The first is the direct effect of relative grain size on the mobility of the various fractions in the mixture. The second is a natural sorting process that occurs when most, or all, of the sizes in the mixture are at least occasionally in motion. This simple, geometrically necessary sorting process

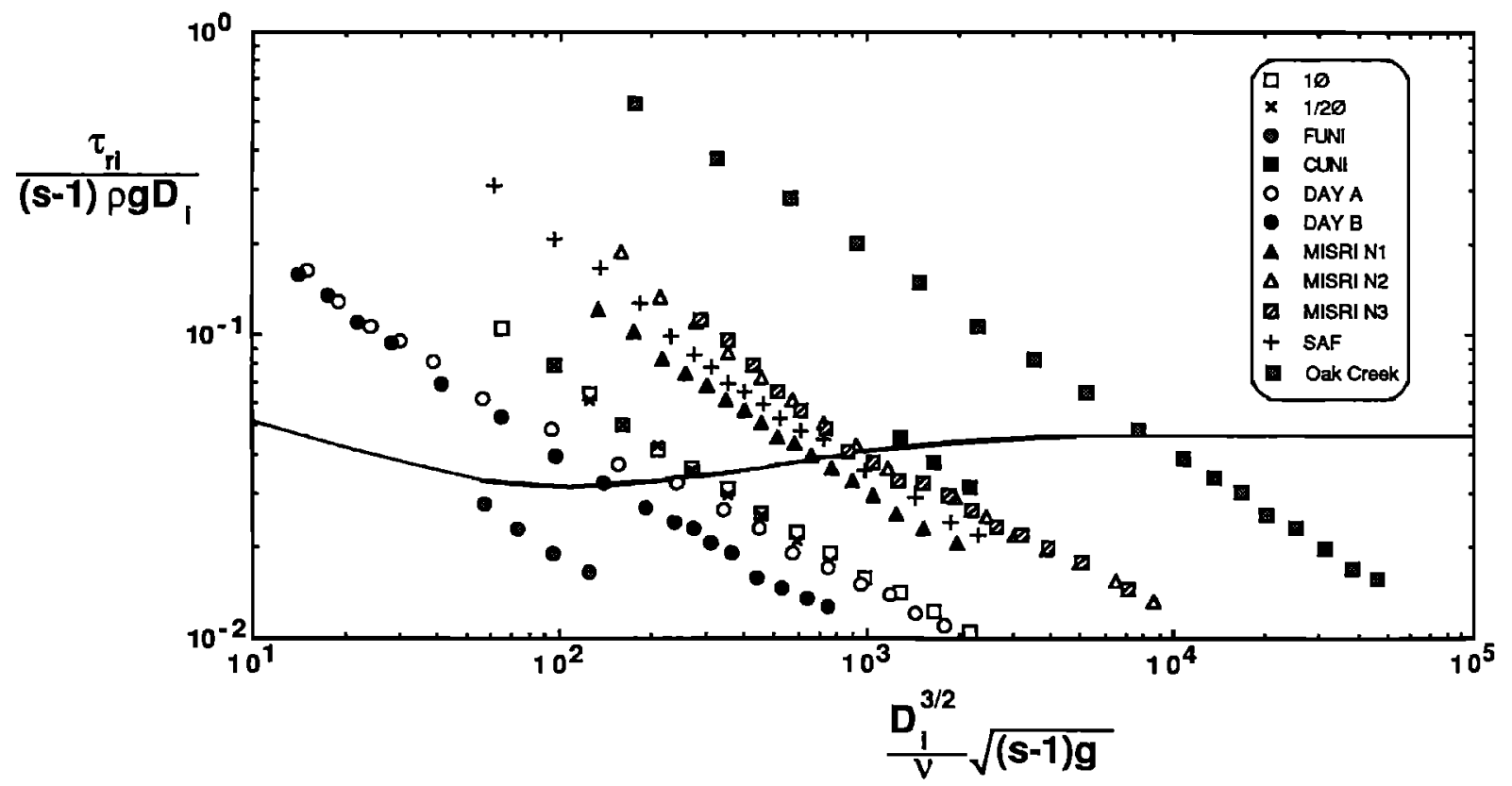

Fig. 9. The $\tau_{r i}{ }^{*}$ as a function of $S^{*}$ for all fractions and sediments. 
occurs because finer grains can fall into positions vacated by coarser grains, while coarser grains do not fit into positions vacated by finer grains [Parker and Klingeman, 1982]. Coarsened surface layers have been observed in the field [Milhous, 1973] and in both sediment feed and recirculating flumes [D hamotharan et al., 1980; Wilcock, 1987]. In an equilibrium sediment feed system, the development of a coarse surface layer is constrained by the mobility of each fraction (for a given bed surface grain size distribution) and the requirement that each fraction is transported at the imposed fractional transport rates. The presence of a coarse surface layer during equilibrium transport in a feed system has been taken as evidence that coarse grains in a mixed-size sediment are inherently less mobile than fine grains and must therefore become overrepresented on the bed surface to make their mobility equal to that of the other fractions in the mixture [Parker and Klingeman, 1982]. The presence of a coarse surface layer in recirculating systems, for which equal mobility is not a constraint, suggests that equilibrium transporting systems in general operate near equal mobility and that little additional adjustment of the bed surface grain size distribution is necessary for sediment feed systems to operate at equilibrium.

It is both an important and convenient result that recirculating transport systems appear to have the same initialmotion relations that are a requirement for sediment feed systems. Natural rivers contain aspects of both systems to a degree that is not entirely understood, but depends to some extent on the time and space scales appropriate to a given problem. The modeling of mixed-size sediment transport in natural situations is considerably simplified if initial-motion conditions are similar for both types of transport systems.

The general applicability of the equal mobility results discussed here is supported by semianalytical models of the critical shear stress of mixed-size sediments. Egiazaroff [1965] developed a model that included the effect of relative grain size on the flow exposure individual fractions in a mixture experience, but did not incorporate any size-dependent resistance to movement. His model showed $\tau_{r i}{ }^{*}$ to be independent of grain size at $D_{i}<D_{m}$ and to vary with the square root of $D_{i}$ at $D_{i}>D_{m}$. A more recent model developed by Wiberg and Smith [1987] incorporates size-dependent grain resistance using the pivoting angle results of Miller and Byrne [1966]. Their model shows $\tau_{r i}^{*}$ to be relatively independent of grain size (near equal mobility) for the coarse sand and gravel sediments examined in this paper.

\section{Controls on $\tau_{\mathrm{rso}}$ *}

Although the relative-size effect on $\tau_{r i}{ }^{*}$ is well-described by only one of $D_{i} / D_{50}$ or percent finer than, there is also variation in the absolute values of $\tau_{r i}{ }^{*}$, as shown by the separation of the fractional plots in Figure 9. Because the $\tau_{r i}{ }^{*}-D_{i} / D_{50}$ curves are quite consistent in form, this displacement can be approximated by the position of only one value of $\tau_{r i}{ }^{*}$ for each mixture. Figure 10 presents the reference shear stresses for $D_{35}$, $D_{50}$, and $D_{65}$ in each mixture as a function of $S^{*}$; the Shields curve is also plotted. The reference shear stresses corresponding to $D_{\text {so }}$ give the closest fit to the Shields cure. Except for one point (SAF), all of these data fall within a factor of 1.4 of the Shields curve, which is the approximate width of data scatter typically found in equivalent unisize plots, including the original diagram by Shields [1936]. Except for two points (SAF and Misri N1), the scatter in the $D_{50}$ points is actually considerably less; these points also follow the trend of the Shields curve reasonably closely, and fall mainly below the Shields curve. That these results are slightly and consistently different from the Shields curve is not surprising, in that the method used here to estimate the reference shear stress is different from that used by Shields [1936]. It has often been noted [e.g., Taylor and Vanoni, 1972] that the Shields curve frequently corresponds to a finite transport rate in unisize sediments. This transport rate is presumably somewhat different from the $W_{i}^{*}=0.002$ criterion used here. The reason why two points (representing the SAF and Misri N1 mixtures) fall well outside the trend defined by the others could not be determined, but is apparently not a function of $D_{50}$, size distribution sorting or shape, relative depth, grain shape or density, or grain Reynolds number. If the two outlying points are ignored, the trend of the remaining points in the $D_{50}$ plot of Figure 10 could be described reasonably well by either a slightly lower position $(\approx 12 \%)$ of the Shields curve or by a simple loglinear trend between $\tau_{r s 0^{*}}$ and $S^{*}$. The choice of a loglinear trend depends primarily on the extreme left- and right-hand points on Figure 10 (representing FUNI and Oak Creek), and could simply be the result of data scatter.

\section{$\tau_{r i}^{*}$ Fitted with the AW Reference-Transport Criterion}

Because the AW transport model directly incorporates parameters not in the PKM model, the reference shear stresses from each method may be compared only approximately. If one assumes that the sediment bed is planar at incipient motion, so that the total bed shear stress and skin friction shear stress (computed with the AW model) are equal, the square of the AW reference shear stress parameter $A^{\prime}$ may be taken to be equal to $\tau_{r i}{ }^{*}$. The square of the $A^{\prime}$ values fitted by Day [1980b] to his data are given in Figure 11 as a plot of $\tau_{r i}{ }^{*}$ against $D_{i} / D_{50}$. For comparison, values of $\tau_{r i}{ }^{*}$ at $W_{i}{ }^{*}=0.002$ for the same data are also plotted. The $\left(A^{\prime}\right)^{2}$ values for bed $\mathrm{A}$ are distinctly curved and gentler in slope than the PKM fit (straight line slopes of -0.56 and -0.81 ). The $\left(A^{\prime}\right)^{2}$ values for bed $B$ are more nearly loglinear, although still gentler in slope than the PKM fit (slopes of -0.84 and -0.96 ). It is worth recalling that the transport data for bed A of Day [1980a] had very few values near the PKM reference transport value of $W_{i}^{*}=0.002$, making the $\tau_{r i}{ }^{*}$ values for this mixture the least certain of all those fitted. For the data of Day [1980a], the AW reference transport criterion corresponds to fractional transport rates considerably greater than $W_{l}^{*}=0.002$, so that the transport rates of both sediments extend to the AW reference transport criterion.

It is not susprising that the $\mathrm{AW}$ reference transport method produces initial-motion results that are different from the PKM method. Different variables are included in each transport parameter. More important, Day [1980b] standardizes the fractional transport parameter (equation (6)) using $p_{i}$, the proportion of each fraction in transport, rather than $f_{t}$, the proportion of each fraction in the bed sediment. Hence the influence of the bed grain size distribution, which is directly incorparated in $W_{i}^{*}$ (equation (5)), is only indirectly included in the $\mathrm{AW}$ reference transport criterion through its influence of the transport grain size distribution. A direct comparison of these two reference transport methods is presented in the work by Wilcock [this issue]. A general reference transport method that can estimate the true mean critical shear stress of individual fractions in a mixed-size sediment is not available at present. Because the two methods give different initial-motion results, and because there is not a clear choice among the methods at present, reliable conclusions on the physics of initial motion can only be made in terms of comparisons among different mixtures, and only then when the different data sets are cast in the same dimensionless framework. Such compari- 

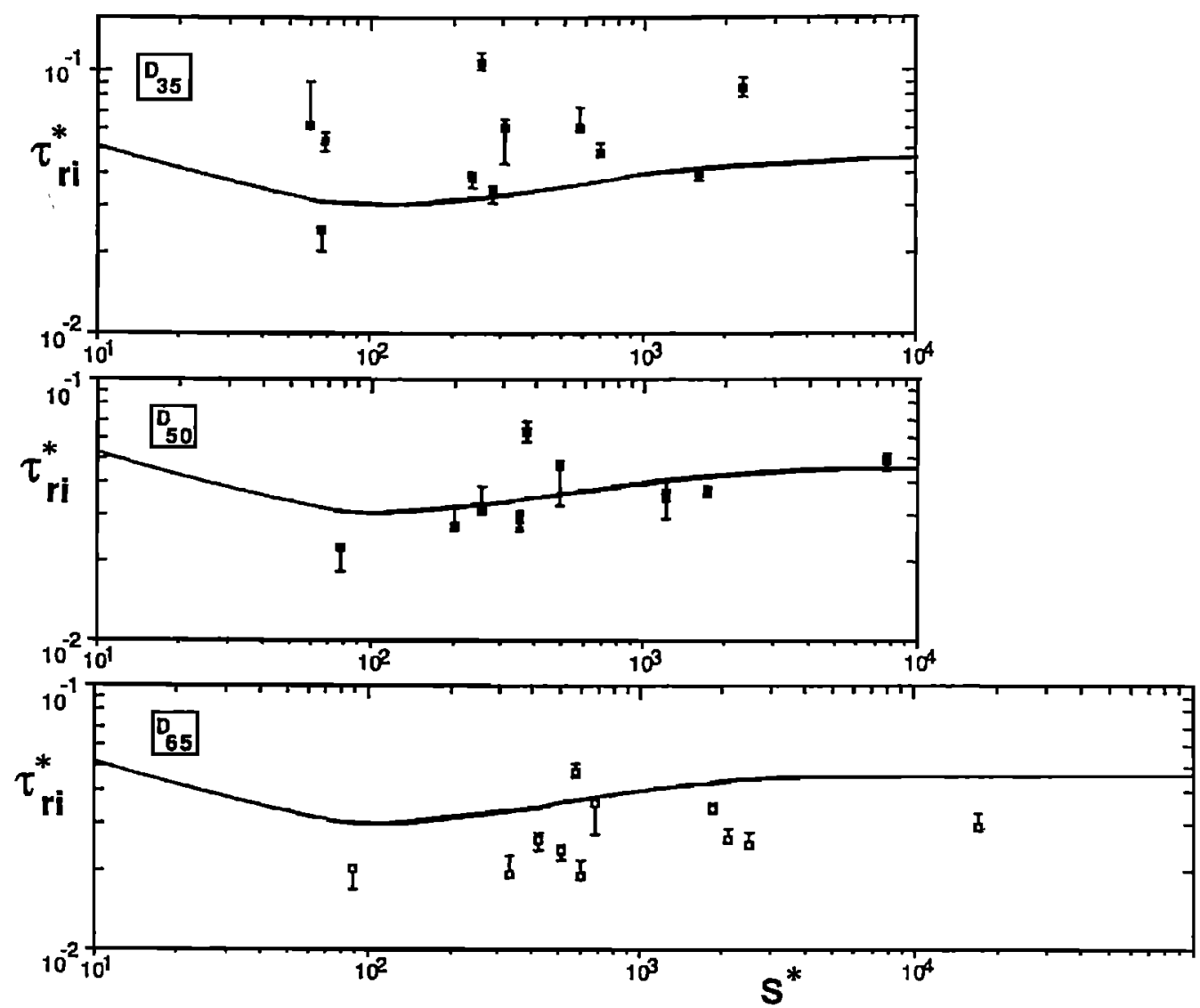

Fig. 10. The $\tau_{r i}^{*}$ as a function of $S^{*}$ for $D_{35}, D_{50}$, and $D_{65}$ and all sediments. Method used to determine error bars described in the section Fitting Techniques.

sons allow the effect of mixture parameters $\left(D_{i} / D_{s 0}\right.$, sorting, skewness, bimodality) to be examined, as well as the natural variability of critical shear stresses in mixed-size sediments to be described. Final conclusions that are based on particular initial-motion results, however, such as the form of $\tau_{\mathrm{ri}}{ }^{*}-D_{i} / D_{\text {so }}$ relations and the existence of equal mobility, must await the development of a general and properly scaled initial-motion method.

\section{CONCLUSIONS}

An explicit experimental test was made of the effect of mixture sorting on the initial motion of individual fractions in size mixture. Using two sediments in which the mixture sorting was the only flow or sediment parameter varied, we found that the reference shear stress, a critical shear stress analogue, is independent of mixture sorting if the effect of $D_{i} / D_{s 0}$ is accounted for. This result was also found in experiments with

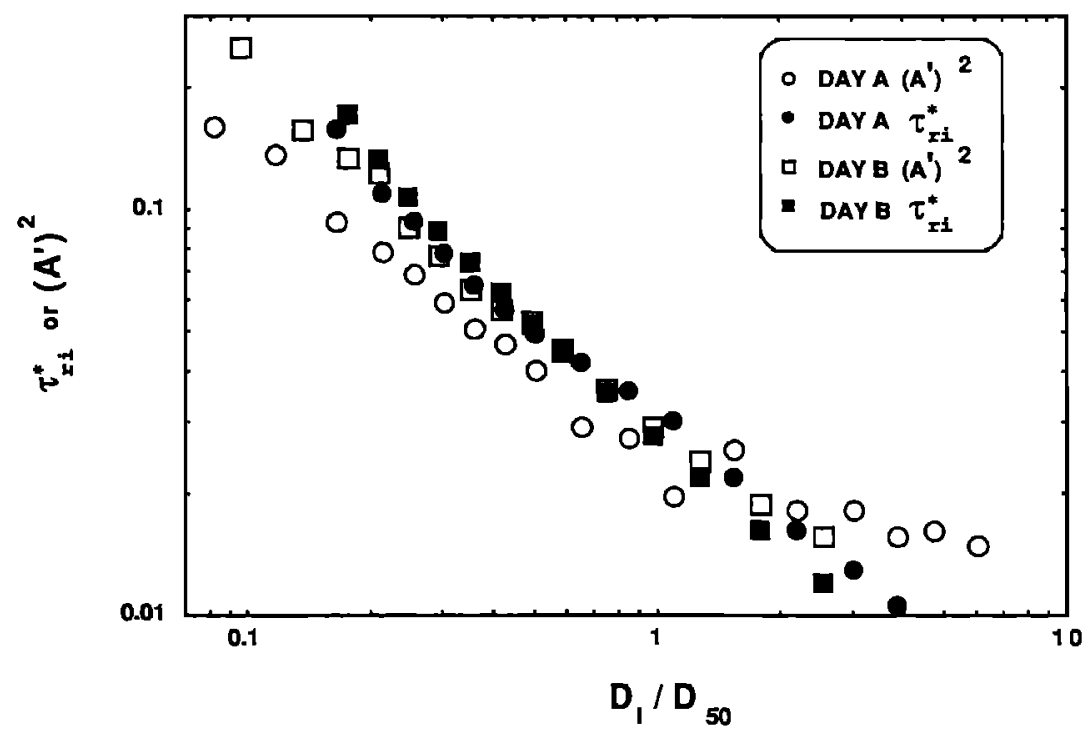

Fig. 11. The initial-motion results for data of Day [1980] using the AW and PKM reference transport criteria. 
sediments for which the mean size varied by a factor of 8 and the sorting varied from $0.2 \phi$ to $1.0 \phi$. We can therefore hypothesize that mixture sorting has little effect on initial motion in other types of sediment mixtures as well. This hypothesis is supported by $\tau_{r i}{ }^{*}-D_{i} / D_{50}$ trends in data from other sources that are essentially similar to our results. Mean grain size, sorting, and size distribution shape for all the data examined in this paper vary over a broad range, yet the form of the $\tau_{\mathrm{r}}{ }^{*}-D_{i} i D_{50}$ trends show no dependence on sorting. In all of these cases, only one of the relative grain size parameters $\left(D_{1} D_{50}\right.$ or percent finer than) is necessary for modeling the initial motion of individual fractions in mixed-size sediment. Of these, $D_{i} / D_{50}$ is preferable because the variation of $\tau_{r i}{ }^{*}$ with $D_{1} D_{50}$ is quite simple and because physical conclusions may be drawn directly from the relation.

The strong similarity in initial-motion conditions for a variety of different sediments and flows is an important and useful result. Very consistent, and surprisingly simple, relations among $\tau_{r i}{ }^{*}, D_{i} / D_{50}$ and $D_{50}$ can be defined for 11 different sediments with a variety of grain size distribution shapes and sorting values from $0.19 \phi$ to $2.1 \phi$, a range that includes most natural sediments. These relations are also consistent with existing relations for the limiting case of unisize sediment. This suggests that the initial-motion relations shown here (and the reference transport methodology used to determine $\tau_{r i}{ }^{*}$ ) may be generally valid. Such a conclusion is supported not only by the consistency in the empirical results, but also by our controlled demonstration that mixture sorting has little effect on fractional initial-motion conditions, once the relative size of each fraction is described by $D_{i} / D_{50}$. Given $D_{i} / D_{50}$, the distribution standard deviation is the mixture parameter that primarily determines the relative position of individual fractions within a mixture. If the sorting has little demonstrated effect on fractional initial-motion conditions, it can be hypothesized that other grain size parameters may have little effect as well. If so, initial-motion relations for individual fractions in most natural sediment mixtures may be adequately described by two general functions, one involving only the size ratio of each fraction and the other the median size of the sediment mixture.

The actual form of the $\tau_{r i}{ }^{*}-D_{i} / D_{50}$ relations depends on the reference transport method used. One reference transport criterion [Ackers and White, 1973$]$ produces $\tau_{r i}{ }^{*}-D_{i} / D_{50}$ relations slightly gentler in slope and, in some cases, somewhat more curved than those produced using the reference transport criterion of Parker et al. [1982]. With the PKM reference transport criterion, the slope of $\tau_{\mathrm{ri}}-D_{j} / D_{50}$ curves for all sediments examined here varies closely about the condition of equal mobility (no dependence of $\tau_{r i}$ on $D_{i}$ ). Although equal mobility is a necessary condition for equilibrium transporting systems which must carry an imposed mixed-size sediment transport rate (feed systems), all of the experimental data examined here are from recirculating systems, for which equal mobility should not be a requirement for steady state transport. Because natural transporting systems exhibit, to an unknown degree, features of both recirculating and sediment feed transport conditions, it is a potentially important and convenient result that recirculating systems appear to produce initialmotion conditions that are similar to those necessary for a feed system.

Acknowledgments. An earlier version of this paper was read by Ole Madsen and Chris Paola, who made suggestions for substantial improvements. Further improvement was inspired by the comments of an anonymous reviewer. The work was supported by the Office of Naval Research under contracts N00014-80-C-0273 and N00014-86K-0325.

\section{REFERENCES}

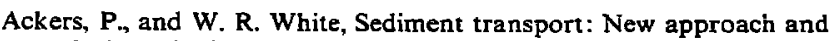
analysis, J. Hydraul. Eng., 99(HY11), 2041-2060, 1973.

Andrews, E. D., Entrainment of gravel from naturally sorted riverbed material, Geol. Soc. Am. Bull., 94, 1225-1231, 1983.

Carling, P. A., Threshold of coarse sediment transport in broad and narrow natural streams, Earth Surf. Processes Landforms, 8, 1-18, 1983.

Day, T. J., A study of the transport of graded sediments, Rep. IT 190 , Hydraul. Res. Stat., Wallingford, England, $1980 a$.

Day, T. J.. A study of initial motion characteristics of particles in graded bed material, Pap. 80-1A, pp. 281-286, Geol. Surv. of Can.. Ottawa, $1980 b$.

Dhamotharan, S., A. Wood, G. Parker, and H. Stefan, Bedload transport in a model gravel stream, Proj. Rep. 19Q, St. Anthony Falls Hydraul. Lab., Univ. of Minn., Minneapolis, 1980.

Egiazaroff, I. V., Calculation of nonuniform sediment concentrations, J. Hydraul. Eng., 91(HY4), 225-247, 1965.

Einstein, H. A., The bedload function for sediment transport in open channel flows, Tech. Bull. 1026, Soil Conserv. Serv., U.S. Dep. of Agric., Washington, D.C., September 1950.

Folk, R. L., Petrology of Sedimentary Rocks, 182 pp., Hemphill, Austin. Tex., 1980.

Hammond, F. D. C., A. D. Heathershaw, and D. N. Langhorne, A comparison between Shields' threshold criterion and the movement of loosely packed gravel in a tidal channel, Sedimentology, 3I, $51-62,1984$.

$\mathrm{Li}, \mathrm{Z}$., and P. D. Komar, Laboratory measurements of pivoting angles for applications to selective entrainment of gravel in a current, Sedimentology, 33, 413-423, 1986.

Meland, N., and J. O. Norrman, Transport velocities of individual size fractions in heterogeneous bed load, Geogr. Ann., Ser. A, 51, 127-144, 1969.

Milhous, R. T., Sediment transport in a gravel-bottomed stream, Ph.D. thesis, Oreg. State Univ., Corvallis, 1973.

Miller, M. C., I. N. McCave, and P. D. Komar, Threshold of sediment motion under unidirectional currents, Sedimentology, 24, 507-527, 1977.

Miller, R. L., and R. J. Byrne, The angle of repose for a single grain on a fixed rough bed, Sedimentology, 6, 303-314, 1966.

Misri, R. L., R. J. Garde, and K. G. Ranga Raju, Bed load transport of coarse nonuniform sediment, J. Hydraul. Eng., $110(3), 312-328$, 1984.

Parker, G., Hydraulic geometry of active gravel rivers, J. Hydraul. Eng., 105(HY9), 1185-1201, 1979.

Parker, G., and P. C. Klingeman, On why gravel bed streams are paved, Water Resour. Res., 18, 1409-1423, 1982.

Parker, G., P. C. Klingeman, and D. L. McLean, Bedload and size distribution in paved gravel-bed streams, J. Hydraul. Eng., JO8(HY4), 544-571, 1982.

Shields, A., Application of similarity principles and turbulence research to bedload movement, Hydrodyn. Lab. Rep. 167, Calif. Inst. of Technol., Pasadena, 1936.

Taylor, B. D., and V. A. Vanoni, Temperature effects in low-transport, flat-bed flows, J. Hydraul. Eng., 97(HY8), 1427-1445, 1972.

Vanoni, V. A., and N. H. Brooks, Laboratory studies of the roughness and suspended load of alluvial streams, Sediment. Lab. Rep. E68, Calif. Inst. Technol., Pasadena, Calif., 1957.

White, W. R., and T. J. Day, Transport of graded gravel bed material, in Gravel-Bed Rivers, edited by R. D. Hey, J. C. Bathurst, and C. R. Thorne, pp. 181-213, John Wiley, New York, 1982.

Wiberg, P. L., and J. D. Smith, Calculations of the critical shear stress for motion of uniform and heterogeneous sediments, Water Resour. Res., 23, 1471-1480, 1987.

Wilcock, P. R., Bed-load transport of mixed-size sediment, Ph.D. dissertation, 205 pp., Mass. Inst. of Technol., Cambridge, 1987.

Wilcock, P. R., Methods for estimating the critical shear stress of individual fractions in mixed-size sediment, Water Resour. Res., this issue.

J. B. Southard, Department of Earth, Atmospheric, and Planetary Sciences, Massachusetts Institute of Technology, Cambridge, MA 02139.

P. R. Wilcock, Department of Geography and Environmental Engineering, The Johns Hopkins University, Baltimore, MD 21218.

(Received August 18, 1987; revised February 29, 1988 . accepted March 4, 1988.) 